\title{
PDGFR $\beta$ is an essential therapeutic target for BRCA1-deficient mammary tumors
}

\author{
Feng Bai ${ }^{1,2,3}$, Shiqin Liư ${ }^{4,3}$, Xiong Liư ${ }^{1,5}$, Daniel P. Hollern ${ }^{6}$, Alexandria Scott ${ }^{3}$, Chuying Wang ${ }^{3,7}$, Lihan Zhang ${ }^{3,8}$,
} Cheng Fan ${ }^{6}$, Li Fu ${ }^{1,9}$, Charles M. Perou ${ }^{6}$, Wei-Guo Zhu ${ }^{10}$ and Xin-Hai Pei ${ }^{1,3,5^{*}}$

\begin{abstract}
Background: Basal-like breast cancers (BLBCS) are a leading cause of cancer death due to their capacity to metastasize and lack of effective therapies. More than half of BLBCs have a dysfunctional BRCA1. Although most BRCA1-deficient cancers respond to DNA-damaging agents, resistance and tumor recurrence remain a challenge to survival outcomes for BLBC patients. Additional therapies targeting the pathways aberrantly activated by BRCA1 deficiency are urgently needed.

Methods: Most BRCA1-deficient BLBCs carry a dysfunctional INK4-RB pathway. Thus, we created genetically engineered mice with Brca1 loss and deletion of p16 $6^{I N K 4 A}$, or separately p18 $8^{\text {INKAC }}$, to model the deficient INK4-RB signaling in human BLBC. By using these mutant mice and human BRCA1-deficient and proficient breast cancer tissues and cells, we tested if there exists a druggable target in BRCA1-deficient breast cancers.

Results: Heterozygous germline or epithelium-specific deletion of Brca1 in p18 $8^{\text {INKAC}}$ - or p16 $6^{\text {INKAA }}$-deficient mice activated Pdgfr $\beta$ signaling, induced epithelial-to-mesenchymal transition, and led to BLBCs. Confirming this role, targeted deletion of Pdgfr $\beta$ in Brca1-deficient tumor cells promoted cell death, induced mesenchymal-to-epithelial transition, and suppressed tumorigenesis. Importantly, we also found that pharmaceutical inhibition of Pdgfr $\beta$ and its downstream target Pkca suppressed Brca1-deficient tumor initiation and progression and effectively killed BRCA1-deficient cancer cells.

Conclusions: Our work offers the first genetic and biochemical evidence that PDGFRß-PKCa signaling is repressed by BRCA1, which establishes PDGFRß-PKCa signaling as a therapeutic target for BRCA1-deficient breast cancers.
\end{abstract}

Keywords: BRCA1, PDGFRß, EMT, Mammary tumor, Targeted therapy

\section{Background}

The heterogeneity of breast cancer is marked by pathologically distinct tumor types that differ in their responsiveness to treatment. In the clinical setting, breast cancer is comprised of three main subtypes: HER2positive, estrogen receptor (ER)-positive luminal, and

\footnotetext{
* Correspondence: peixinhai@szu.edu.cn

${ }^{1}$ Guangdong Provincial Key Laboratory of Regional Immunity and Diseases, International Cancer Center, Shenzhen University Health Science Center, Shenzhen 518060, China

${ }^{3}$ Dewitt Daughtry Family Department of Surgery, University of Miami, Miami, FL 33136, USA

Full list of author information is available at the end of the article
}

basal-like cancers (BLBCs) that make up the majority of triple-negative breast cancer [TNBC; ER, PR, HER2 negative by immunohistochemistry (IHC) analysis] [1, 2]. BLBCs are highly heterogeneous and aggressive, perhaps due to their enrichment of tumor-initiating cells (TICs) or cancer stem cells that are thought to drive clinical relapse and metastasis [3-6]. TICs and tumor cells with mesenchymal features have enhanced capacity to metastasize and are resistant to radio- and chemotherapy [7]. Mammary TICs can be generated from luminal tumor cells by an epithelial-to-mesenchymal transition (EMT) program [7-15], a process in which 
epithelial cells lose many of their epithelial characteristics and acquire mesenchymal features [7]. BLBCs likely originate from luminal progenitors [8-11] and contain a number of distinct cell types including cells that express luminal biomarkers [16-18]. Notably, more than half of BLBCs are associated with functional loss of BRCA1, caused by germline or somatic mutation or by promoter hypermethylation [19-22]. BRCA1 is a tumor suppressor that functions in DNA damage repair. Although the majority of BRCA1-deficient cancer patients respond to DNA-damaging agents such as cisplatin and poly (ADPribose) polymerase (PARP) inhibitors, tumor recurrence and resistance, likely driven by TICs, combine to decrease the 5-year survival of such patients [23, 24]. Thus, additional therapies targeting the pathways aberrantly activated by BRCA1 deficiency are urgently needed.

In addition to BRCA1 loss, many of the DNArepair-deficient TNBCs also harbor a dysfunctional INK4-RB pathway [21, 25-27]. Key participants in this pathway are $\mathrm{p} 16^{I N K 4 A}(\mathrm{p} 16)$ and $\mathrm{p} 18^{\mathrm{INK4C}}(\mathrm{p} 18)$. These two members of the inhibitors of the CDK $4 / 6$ (INK4) family inhibit CDK4 and CDK6, whose activation phosphorylates and functionally inactivates the $\mathrm{RB}$ family of proteins (RB, p107, p130) [26]. Importantly, p16 is inactivated in $\sim 30-60 \%$ of breast cancers, and p18 expression is reduced in these cancers $\{[21,28-30]$ and Bai unpublished data $\}$. We and others have reported that BRCA1 deficiency in human and mouse mammary epithelial cells (MECs) activates the $\mathrm{p} 16$ and $\mathrm{p} 18$, inducing premature senescence [11, 31-34]. Finally, we have demonstrated that loss of $p 16$ or $p 18$ rescues the premature senescence of MECs caused by Brca1 deficiency [11, 31, 33, 34] and that loss of Brca1 in p16- or p18-deficient mice leads to the development of mammary tumors resembling BLBC accompanied by features of EMT [11, 31].

PDGFR $\beta$, a receptor for members of the plateletderived growth factors (PDGFs), is abundantly expressed in stromal fibroblasts [35-37]. PDGFR $\beta$ signaling plays a critical role in activating cancerassociated fibroblasts (CAFs) which facilitate breast cancer growth and progression [35, 38, 39]. Notably, PDGFR $\beta$ expression is specifically upregulated in late-stage breast cancer cells [40-42]. PDGFR $\beta$ activates PKC $\alpha$ which then phosphorylates FRA1, a key EMT-inducing transcription factor (EMT-TF), and drives TIC function of transformed MECs [43, 44]. Inhibition of PDGFR $\beta-P K C \alpha$ signaling specifically targets oncogene-transformed MECs that have undergone EMT and induces mesenchymal-toepithelial transition (MET), suppressing tumor initiation and progression [40, 44, 45]. It remains elusive how PDGFR $\beta$ signaling is involved in epithelial tumorigenesis. For example, whether PDGFR $\beta$ signaling activates EMT in a tumor cell autonomous manner and whether PDGFR $\beta$-PKC $\alpha$ signaling is required for survival and for maintaining mesenchymal status of the tumor cells in vivo are key unanswered questions that may inform treatment strategies for breast cancer.

In this study, we examined the molecular outcomes of BRCA1 deficiency combined with loss of either p16 or p18 to identify targetable pathways in BRCA1/INK4-RBdeficient tumors. This identified activation of the Pdgfr $\beta$ pathway as potential driver in these tumors. Further, we showed preclinical evidence that these molecular alterations in Pdgfr $\beta$ pathway could be effectively therapeutically targeted.

\section{Methods}

Mice, histopathology, and immunostaining

$\mathrm{Brcal}^{f / f}$ and Tg (MMTV-Cre) 4Mam mice were obtained from the NCI Mouse Repository and JAX lab, respectively $[46,47]$. The generation of $p 16^{-/-}, p 18^{-/-}, \mathrm{Brcal}^{+/-}$, Brcal $^{\text {MGKO }}\left(\right.$ Brcal $^{f f f} ;$ MMTV-Cre or Brcal ${ }^{f /-}$;MMTVCre) mice was described previously [31, 48-50]. The Institutional Animal Care and Use Committee at the University of Miami and Shenzhen University approved all animal procedures. Histopathology and immunohistochemistry (IHC) were performed as described previously $[11,28,31]$. The primary antibodies used were Ck14, cleaved caspase 3 (Thermal Scientific), PDGFR $\beta$, phosphorylated PKC $\alpha(\mathrm{p}-\mathrm{PKC} \alpha)$, phosphorylated FRA1 (pFRA1), FRA1 (Cell signaling), ER $\alpha$, BRCA1 (Santa Cruz), E-cadherin (E-cad), PKC $\alpha$ (BD Biosciences), and Vimentin (Vim) (Abcam). Immunocomplexes were detected by using the Vectastain $\mathrm{ABC} D \mathrm{DAB}$ kit according to the manufacturer's instructions (Vector Laboratories) or by using FITC- or rhodamine-conjugated secondary antibodies (Jackson Immunoresearch).

\section{Mammary tumor cell preparation and tumorsphere formation assay}

Mammary tumors were dissected and tumor cell suspensions were prepared as previously described [11, $28,31]$. For the primary and secondary tumorsphere formation assays, primary $p 18^{-/-} ; \mathrm{Brcal}^{M G K O}$ mammary tumor cells were plated onto six-well, ultra-low attachment plates, in serum-free DMEM-F12 supplemented with B27, EGF, and bFGF as described $[28,31]$. Primary tumorspheres formed were collected and dissociated after 9 days of culture. $10^{4}$ cells dissociated from the primary tumorsphere were plated in triplicate with or without treatment. Secondary tumorspheres that formed after 6 days of culture were counted under the microscope. 
Cell culture, cell viability assay, overexpression of BRCA1, CRISPR-mediated Pdgfr $\beta$ knockout, drug treatment, and annexin $\mathrm{V}$ analysis

T47D, HCC1937, MCF7, SUM149, MDA-MB231, and BT20 cells were cultured per ATCC recommendations. To determine cell viability, 50,000 cells were plated in 24-well plates and treated with DMSO, PDGFR tyrosine kinase inhibitor III (PDGFR inh III, EMD Biosciences) $[44,51]$, or RO31-8220, a specific PKC $\alpha$ inhibitor (Cayman Chemical) $[44,52]$, at the indicated concentrations. Viable cell numbers were determined by an automatic cell counter (Bio-rad). Dead cells were determined by trypan blue or propidium iodide (PI) staining, and the percentage of dead cells was calculated from at least 1000 cells. For ectopic expression of BRCA1, cells were transfected with pBabe-empty, pBabe-HA-BRCA1, or pBabe-Myc-BRCA1 as previously described [31]. For CRISPR-mediated Pdgfr $\beta$ knockout (KO) in primary tumor cells, Pdgfr $\beta$ CRISPR/Cas9 KO plasmids (mouse) (Santa Cruz, SC-422171) were transfected into $p 18^{-/-}$; $B r c a 1^{M G K O}$ primary tumor cells following the manufacturer's protocol. GFP-positive and GFP-negative cells were sorted 2 days after transfection on a BD FACS SORP Aria-IIu machine for further analysis. For annexin $\mathrm{V}$ analysis, $p 18^{-/-} ; B r c a 1^{M G K O}$ tumor cells were transfected with the Pdgfr $\beta$ CRISPR/Cas9 KO plasmids, and $48 \mathrm{~h}$ after transfection, cells were stained with annexin V-pacific blue (Biolegend) and analyzed by the LSR-Fortessa machine (BD Pharmingen). Data analysis was performed using Kaluza software (Beckman Coulter).

\section{Transplantation and tumor treatment}

For in vivo transplantation, $p 18^{-/-} ; B r c a 1^{M G K O}$ primary tumor cells transfected with the Pdgfr $\beta$ CRISPR/Cas9 KO plasmids were FACS sorted. Six thousand GFP ${ }^{\text {neg }}$ and $\mathrm{GFP}^{\mathrm{pos}}$ live cells (trypan blue negative) were suspended in a $50 \%$ solution of Matrigel (BD) and then inoculated into the left and right inguinal mammary fat pads (MFPs) of 6-week-old female NSG mice (Jackson Laboratory), respectively. Four weeks after transplantation, animals were euthanized and mammary tumors were dissected for histopathological and immunohistochemical analyses. For ex vivo transplantation, primary $p 18^{-/-} ;$Brcal $^{\mathrm{MGKO}}$ tumor cells were cultured to generate primary tumorsphere. $10^{4}$ cells dissociated from primary tumorspheres were treated with DMSO, Ro-31-8220, or PDGFR inh III for 6 days. One thousand live cells were transplanted into MFPs of NSG mice. Four weeks after transplantation, animals were euthanized and mammary tumors were analyzed. For treatment of established mammary tumors, $18^{-/-} ;$Brcal $^{\mathrm{MGKO}}$ tumor cells were transplanted into MFPs of NSG mice and allowed to reach $\sim 200 \mathrm{~mm}^{3}$ in size. Mice were then treated with daily i.p. injection of the agents, and the tumor size was determined.

\section{Microarray analysis, western blot, and ChIP assay}

RNA was extracted and purified from tumors using an RNeasy kit (Qiagen). Tumor RNA was reverse transcribed, amplified, and labeled with Cy5, and WT mammary tissue reference RNA was reverse transcribed, amplified, and labeled with Cy3. The amplified sample and reference were co-hybridized to Agilent $4 \times 180 \mathrm{k}$ custom mouse microarrays and were analyzed as described previously [14, 53]. Murine tumor gene expression data was deposited at the Gene Expression Omnibus under accession number GSE155239. Single sample gene set enrichment analysis (ssGSEA) was performed using GenePattern [54]. The gene signature for PDGF signaling was taken from Reactome [55], while EMT and mammary stem cell signatures were published [56, 57].

For the western blot, tissue and cell lysates were prepared as previously reported [28, 31]. The primary antibodies used were BRCA1 (Santa Cruz), E-cad, Vim, PDGFR $\beta$, p-PDGFR $\beta, p-P K C \alpha, p-F r a 1$ and Snail (Cell signaling), Gapdh (Ambion), and Twist (Abcam). ChIP assays were carried out as previously described [28, 31]. Briefly, T47D and HCC1937 cells were treated with $1.5 \%$ formaldehyde and sonicated. AntiBRCA1 antibody (D-9, Santa Cruz) or control mouse IgG was used to precipitate chromatin associated with BRCA1. Q-PCR was performed to determine the relative abundance of target DNA. Specific primers for the analysis of BRCA1 binding to PDGFR $\beta$ are listed in Additional file 1.

\section{Human tumor samples and gene expression datasets}

Formalin-fixed paraffin-embedded (FFPE) human breast cancer samples lacking patient-identifying information were obtained with IRB approval from the Tissue Banks at the University of Miami and the Department of Pathology at Shenzhen University. All samples obtained were non-treated invasive breast cancers with known ER status. The MetaBric human breast cancer dataset [58] was analyzed for correlation between BRCA1 with PDGFR $\beta$ and PKC $\alpha$ mRNA levels.

\section{Statistical analysis}

All data are presented as the mean \pm SD for at least three repeated individual experiments for each group. Quantitative results were analyzed by the two-tailed Fisher exact test or two-tailed Student's $t$ test. $p<0.05$ was considered statistically significant. 


\section{Results}

Heterozygous germline deletion of Brca1 in p18-deficient mice leads to basal-like tumors with activation of EMT and increase of Pdgfr $\beta$

We previously discovered that the majority of $p 18^{-/-}$ mice developed $\mathrm{CK}^{+}$and $\mathrm{ER}^{+}$luminal type mammary tumors while most $p 18^{-/-} ; \mathrm{BrCa1}^{+/-}$mice formed mammary tumors that were $\mathrm{ER}^{-}$and $\mathrm{CK} 5^{+}$basal-like tumors expressing mesenchymal markers as well as EMT-TFs $[11,28,31]$. In addition, $p 18^{-/-} ; B_{B C a 1^{+/-}}$mammary tumors were enriched with cancer stem cells [31, 59] and significantly more metastatic than $p 18^{-/}$tumors (Fig. 1a). These data suggest that heterozygous germline deletion of Brca1 induces basal-like tumors with activation of EMT and promotes metastasis. To further explore the role of PDGFR $\beta$ signaling in activating EMT and promoting tumor initiation and progression [40, 44, 45 , we performed a microarray analysis of mammary tumors from $p 18^{-/-}$and $p 18^{-/-} ; \mathrm{Brcal}^{+/-}$mutant mice. Analysis of differentially expressed genes identified Pdgfr $\beta$ mRNA to be significantly higher in $\mathrm{p} 18^{-/-}$; $\mathrm{BrCa}^{+/-}$tumors than in $\mathrm{p}^{-/-}$tumors (Fig. 1b). We then performed IHC analysis and detected that $75 \%$ $(n=16)$ of $p 18^{-/-} ; \mathrm{Brca}^{+/-}$tumors expressed Pdgfr $\beta$, whereas only $16 \%(n=19)$ of $p 18^{-/-}$tumors yielded similar results. Strong Pdgfr $\beta$ expression ranged from 2

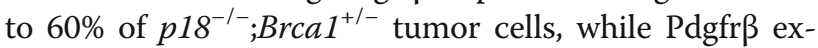
pression was found in $2-5 \%$ of $p 18^{-/-}$tumor cells and was much weaker in intensity. All the EMT-positive

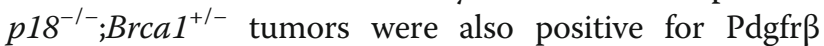
(Fig. 1a, c). We also noted $p 18^{-/-} ; \mathrm{Brcal}^{+/-}$tumor cells that had invaded into muscles were marked by high levels of Pdgfr $\beta$ expression (Fig. 1c). Taking advantage of the majority of $p 18^{-/-} ; B r c a 1^{+--}$tumors expressing a high level of $\operatorname{Pdgfr} \beta$ and a few of these tumors expressing a low level of Pdgfr $\beta$, we performed ssGSEA and found that the lowest Pdgfr $\beta$ samples had lower Pdgf signaling as expected (Fig. 1d, Additional file 2A). Furthermore, Pdgfr $\beta$ mRNA levels in $p 18^{-/-} ; \mathrm{Brca1}^{+/-}$mammary tumors strongly correlated with EMT and stem cell signatures (Fig. 1e, f, and Additional file 2B, C, D), in agreement with the data derived from IHC and published elsewhere $[31,59]$. Together, these results suggest that germline deletion of Brca1 in a $p 18^{-/-}$background activates EMT in mammary tumorigenesis, which is associated with an increase of Pdgfr $\beta$ and Pdgfr $\beta$-activated signaling pathway.

Specific deletion of Brca1 in p18 and p16 null epithelium activates Pdgfr $\beta$-Pkca signaling and EMT inducing metastatic basal-like tumors

Pdgfr $\beta$ is abundantly expressed in stromal fibroblasts which also play an important role in facilitating breast cancer growth and progression $[35,38,39]$. To confirm the role of Brca1 loss in regulating Pdgfr $\beta$ in mammary epithelial and carcinoma cells, and to rule out the effect of stromal Pdgfr $\beta$ regulated by Brca1 loss in mammary tumorigenesis, we generated Brcal $^{\text {MGKO }}$ (Brcal ${ }^{f / f}$;MMTV-Cre or Brcal ${ }^{f /-}$;MMTVCre), $p 18^{-/-} ;$Brcal $^{M G K O}$, and $p 16^{-/-} ;$Brcal $^{M G K O}$ mice in the Balb/c-B6 mixed background in which Brca1 was specifically deleted in mammary epithelia. We previously reported the successful deletion of Brca1 and the activation of EMT in mammary epithelia of $p 18^{-/-} ; \mathrm{Brca1}^{M G K O}$ and $p 16^{-/-} ; \mathrm{Brca}^{M G K O}$ mice [31]. We found that $47 \%(n=15)$ of $p 18^{-1-}, 73 \%(n=15)$

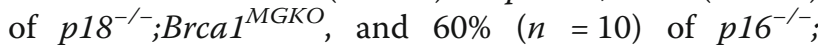
Brca $1^{M G K O}$ mice in the Balb/c-B6 mixed background developed mammary tumors, whereas only $8 \%(n=$ 13) of $\mathrm{Brcal}^{M G K O}$ and no $p 16^{-/-}$mice did so at similar ages (Table 1$)$. Notably, 36\% $(n=11)$ of $p 18^{-/-}$; Brca $1^{M G K O}$ and $50 \%(n=6)$ of $p 16^{-/-} ;$Brcal $^{M G K O}$ tumors, but no $p 18^{-1-}$ tumors, metastasized to the lung (Table 1), consolidating the role of loss-of-function of Brca1 in promoting tumor metastasis.

Though the mammary tumor incidence of $p 18^{-/-}$mice in the Balb/c-B6 background was lower than that of the Balb/c background, $p 18^{-/-}$tumors in the Balb/c-B6 background were also predominantly luminal (Fig. 1a and Table 1) $[28,31]$. Eighty-two percent $(n=11)$ of $p 18^{-/-} ;$Brca $1^{M G K O}$ and all of $p 16^{-/-} ;$Brca $^{M G K O}$ tumors were positive for Vim, EMT-TFs, and Pdgfr $\beta$, whereas only $29 \%(n=7)$ of $p 18^{-/-}$tumors were positive for these features. Further, comparing these $p 18^{-/-} ;$Brcal $^{M G K O}$ and $p 16^{-/-} ; B r c a 1^{M G K O}$ tumors with $\mathrm{p} 18^{-/-}$tumors, we identified more tumors with high $\mathrm{p}-\mathrm{Pkc} \alpha$ and $\mathrm{p}$-Fra1 which together indicated Pdgfr $\beta$ pathway activity in Brca1-deficient tumors (Table 1, Fig. 2a-c).

Implying epithelial origin, most $\operatorname{Pdgfr} \beta$-positive $p 18^{-/-}$; Brca1 $1^{M G K O}$ and $p 16^{-/-} ; B r c a 1^{M G K O}$ mammary tumor cells were also positive for $\mathrm{Ck} 14$, an epithelial marker. Notably, Pdgfr $\beta$ and Ck14 doubly positive tumor cells were also detected in lung metastases of $p 18^{-/-}$; Brca1 $1^{M G K O}$ and $p 16^{-/-} ;$Brca1 $1^{M G K O}$ mammary tumors (Fig. 2a, b, and Additional file 3), which demonstrated that the metastases were derived from Brca1-deficient basal-like mammary tumors with an increased Pdgfr $\beta$ expression. Using western blots to assess protein, we found that the expression of Pdgfr $\beta, \mathrm{p}-\mathrm{Pkc} \alpha$, and $\mathrm{p}$-Fra1 was clearly increased in $p 18^{-/-} ; B r c a 1^{M G K O}$ tumors relative to that of adjacent tumor-free mammary tissues in the same mice or to $p 18^{-/-}$tumors (Fig. 2d, Additional file 4), and in $p 18^{-/-} ; B r c a 1^{M G K O}$ tumor cells relative to that in $p 18^{-/-}$tumor cells (Fig. 2e). As a whole, these data suggest that loss of Brcal induces EMT and metastatic basal-like tumors in an epitheliumautonomous manner and that Brca1 loss activates Pdgfr $\beta-P k c \alpha$ signaling in epithelial tumor cells thereby 
a

\begin{tabular}{|l|c|c|c|c|}
\hline Genotype & $\begin{array}{c}\text { Mammary } \\
\text { Tumor \# }\end{array}$ & $\begin{array}{c}\text { Metastatic } \\
\text { tumor \# }\end{array}$ & $\begin{array}{l}\text { EMT+ } \\
\text { Tumor \# }\end{array}$ & $\begin{array}{c}\text { Pdgfr }+ \\
\text { tumor \# }\end{array}$ \\
\hline WT & $1 / 10$ & $0 / 1$ & $0 / 1$ & $0 / 1$ \\
\hline p18 & $19 / 23$ & $1 / 19$ & $3 / 19$ & $3 / 19$ \\
& $(83 \%)$ & $(5 \%)$ & $(16 \%)$ & $(16 \%)$ \\
\hline Brca1 $^{-/ /}$ & $1 / 11$ & $0 / 1$ & $1 / 1$ & $1 / 1$ \\
\hline p18 $^{/-} ;$Brca $^{+/-}$ & $16 / 20$ & $6 / 16$ & $12 / 16$ & $12 / 16$ \\
& $(80 \%)$ & $(38 \%)^{*}$ & $(75 \%)^{*}$ & $(75 \%)^{*}$ \\
\hline
\end{tabular}

b

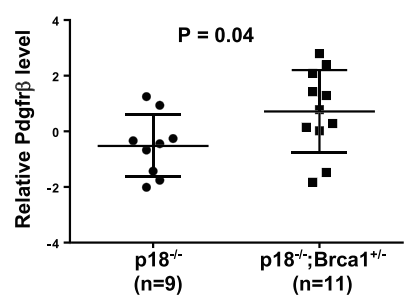

C
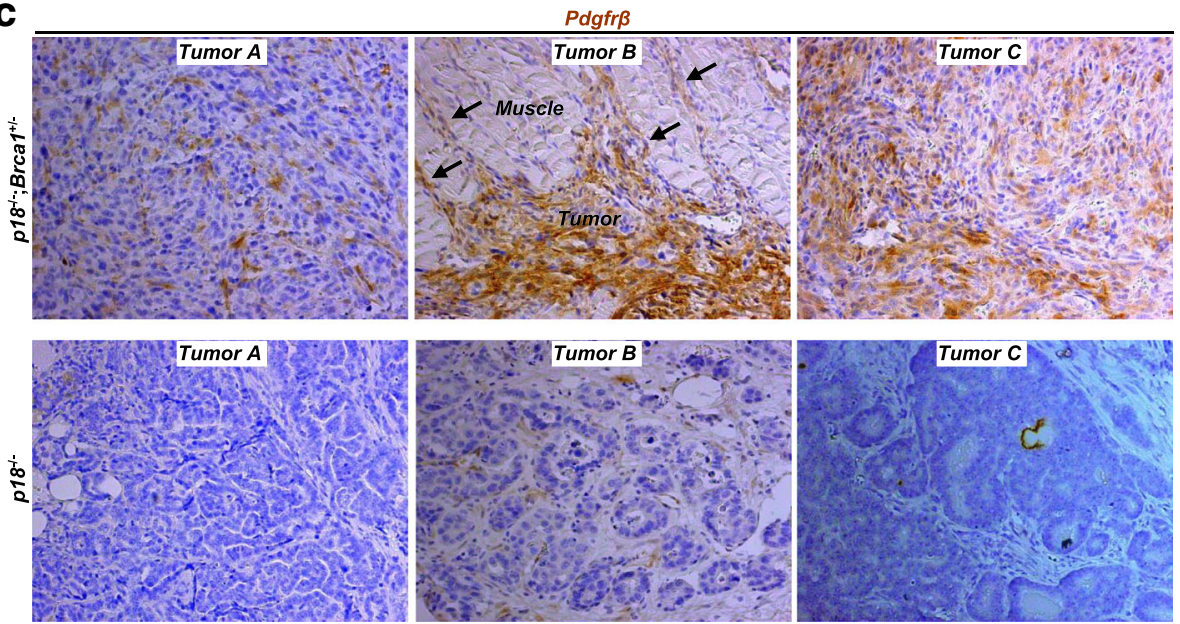

d

e
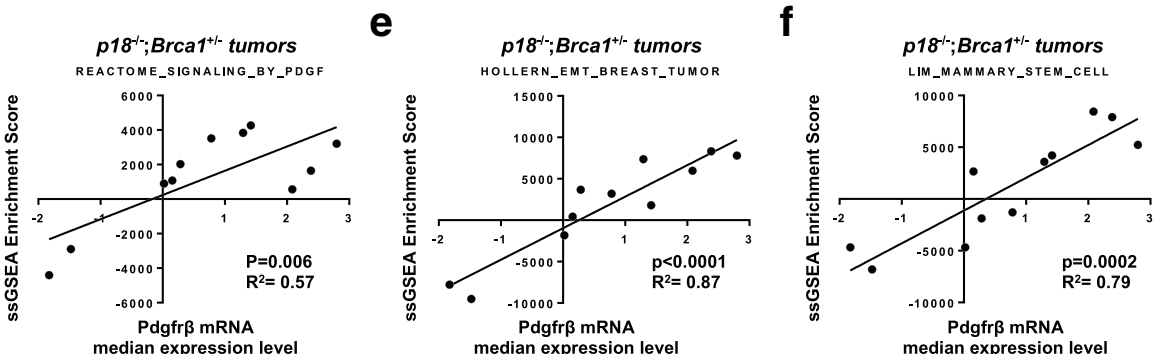

Fig. 1 Heterozygous germline deletion of Brca1 in p18-deficient mice activates EMT with increase of Pdgfr $\beta$ in mammary tumors. a Summary of mammary tumors in mice with Balb/c background. Metastasis was found in the lung. EMT + tumors are defined as tumors that exhibit two of the following: decreased E-Cad, increased Vim, Fn1, or Cd29, and are positive for two EMT-transcription factors (Twist, Snail, Slug, Foxc2, or Fra1) in > $2 \%$ of cells. Pdgfr $\beta+$ tumors are tumors that are positive for Pdgrf $\beta$ in $>2 \%$ tumor cells. The asterisk $\left(^{*}\right)$ denotes a significance from p $18^{-/-} ; \mathrm{BrCa}^{+/-}$and $p 18^{-/-}$tumors by a two-tailed Fisher's exact test. b Microarray analysis of tumors. Boxplot showing relative Pdgfr $\beta$ mRNA levels in $p 18^{-/-} ; \mathrm{BrCa}^{+/-}(n=11)$ and $p 18^{-/-}(n=9)$ tumors. c Representative immunostaining of mammary tumors from a $p 18^{-/-}$and two $p 18^{-/-} ; \mathrm{BrCa}^{+/-}$mice. Note that $p 18^{-/-} ; \mathrm{Brca}^{+/-}$tumor cells that invade into surrounding muscle are strongly positive for Pdgfr $\beta$ (tumor B in top panel) and that most Pdgfr $\beta$-positive cells in $p 18^{-/-}$tumors are stromal cells (tumor B in bottom panel). Pdgfr $\beta$-positive $p 18^{-/-} ; B r c a 1^{+/-}$tumor cells at the tumor invasion front are indicated. $\mathbf{d}-\mathbf{f} X-Y$ plot showing the relation of Pdgfr $\beta$ mRNA and ssGSEA enrichment scores for signatures of Pdgf signaling activity [55] (d), EMT in breast cancers [56] (e), and mammary stem cells [57] (f)

enriching the number of tumor cells with EMT-like features.

\section{BRCA1 inhibits PDGFRß-PKCa signaling and EMT}

To confirm the role of BRCA1 in controlling Pdgfr $\beta$ Pkc $\alpha$ signaling, we overexpressed WT BRCA1 in two BRCA1-mutant breast cancer cell lines, HCC1937 and SUM149, and a basal-like cell line, MDA-MB231. BRCA1 inhibited the mRNA and protein levels of PDGFR $\beta$ indicating BRCA1 repressed transcription of
PDGFR $\beta$ (Fig. 3a, b, and Additional file 5). Consistently, the level of phosphorylation of PKC $\alpha$ was also reduced in BRCA1-overexressed cells confirming that BRCA1 suppressed PDGFR $\beta-P K C \alpha$ signaling (Fig. 3a, b, and Additional file 5). Furthermore, we found that overexpression of BRCA1 in these cells induced expression of CDH1 (encoding E-cadherin) while inhibiting expression of FOSL1 (encoding FRA1) and VIM, consistent with our finding that deficiency of Brcal induced EMT in tumor cells. Importantly, these results confirm the role 
Table 1 Specific deletion of Brca1 induces mammary tumors with activation of Pdgfr $\beta$ signaling in p18-and p16-deficient mice

\begin{tabular}{|c|c|c|c|c|c|c|}
\hline Genotype $^{1}$ & Mammary tumor \# & Metastatic tumor $\#^{3}$ & EMT+ tumor $\#^{4}$ & Pdgfr $\beta+$ tumor $\#^{5}$ & p-Pkca+ tumor $\#^{6}$ & p-Fra1+ tumor $\#^{6}$ \\
\hline WT & $0 / 9$ & & & & & \\
\hline$p 18^{-1-}$ & $7 / 15$ (47\%) & $0 / 7$ & 2/7 (29\%) & 2/7 (29\%) & 2/7 (29\%) & $2 / 7(29 \%)$ \\
\hline $\mathrm{BrCal}^{\mathrm{MGKO2}}$ & $1 / 13(8 \%)$ & $0 / 1$ & $1 / 1$ & $1 / 1$ & $1 / 1$ & $1 / 1$ \\
\hline p18 $8^{-/} ;$Brcal $^{\text {MGKO }}$ & $11 / 15(73 \%)$ & $4 / 11(36 \%)$ & $9 / 11(82 \%)^{*}$ & $9 / 11(82 \%)^{*}$ & $9 / 11(82 \%)^{*}$ & $9 / 11(82 \%)^{*}$ \\
\hline p16 & $0 / 20$ & & & & & \\
\hline p16 ${ }^{-1} ; \mathrm{BrCal}^{\mathrm{MGKO}}$ & $6 / 10(60 \%)$ & $3 / 6(50 \%)$ & $6 / 6(100 \%)$ & $6 / 6(100 \%)$ & $6 / 6(100 \%)$ & $6 / 6(100 \%)$ \\
\hline
\end{tabular}

${ }^{1}$ All mice were in Balb/c-B6 mixed background

${ }^{2} \mathrm{BrCa1}^{\mathrm{MGKO}}, \mathrm{BrCa}^{\mathrm{f} / \mathrm{f}}$;MMTV-Cre, or BrCa ${ }^{\mathrm{f} / \text {; }}$;MMTV-Cre

${ }^{3}$ Metastasis was found in the lung

${ }^{4}$ At least two EMT markers (decreased E-Cad, increased Vim, Fn1, Sma or Cd29) or two EMT-TFs, which included Twist, Slug, Snail, Foxc1, and Foxc2, were detected in $>2 \%$ tumor cells by IHC

${ }^{5}$ Tumors that had $>2 \%$ positive Pdgfr $\beta$ cells by IHC, or primary $p 18^{-/} ; B r c a 1^{M G K O}$ and $p 16^{-/} ; B r c a 1^{M G K O}$ tumor cells at passage 1 expressed fivefolds more Pdgfr $\beta$

than $p 18^{-/-}$tumor cells by western blot analysis (see Fig. 2e)

${ }^{6}$ Tumors that had $>2 \%$ positive $\mathrm{p}$-Pkca or $\mathrm{p}$-Fra1 cells by IHC

${ }^{*}$ A significance from $p 18^{-/} ; B r c a 1^{M G K O}$ and $p 18^{-/-}$tumors by a two-tailed Fisher's exact test

a
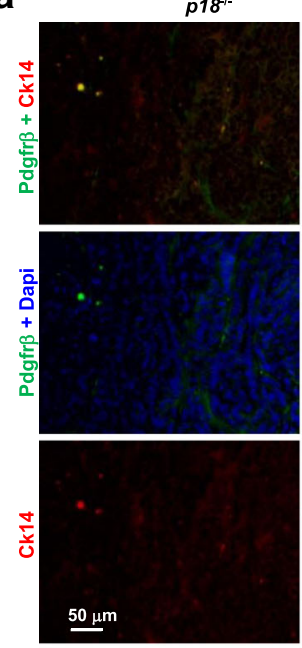

d

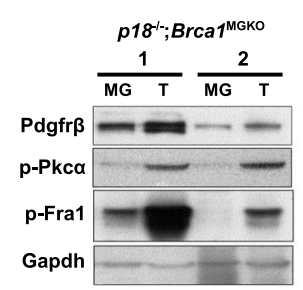

p18 $^{-1} ;$ Brca $^{\text {MGKo }}$
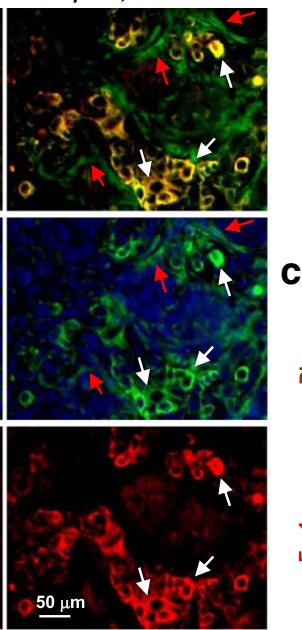

b

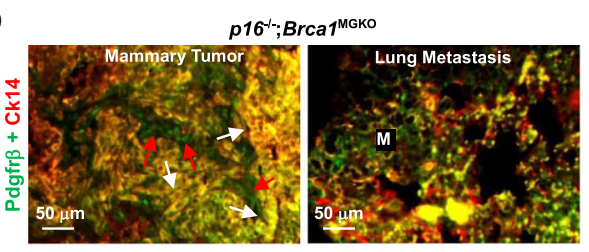

C $p 18^{-1}$ p18-- ;Brca1 ${ }^{\text {MGKo }}$ p16 ${ }^{-1-} ;$ Brca1 $^{\text {мGко }}$

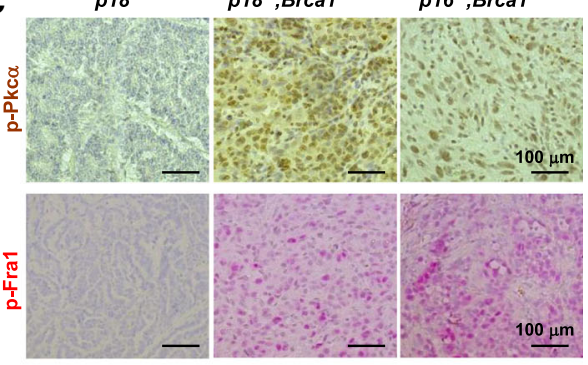

e
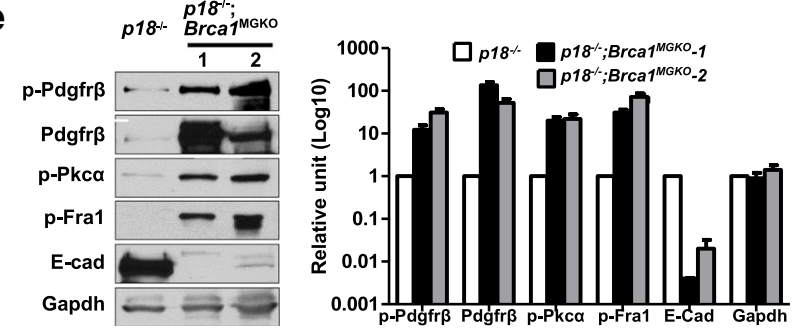

Fig. 2 Deletion of Brca1 in $p 18^{-/-}$or $p 16^{-1-}$ epithelia activates Pdgfr $\beta$-Pkca signaling and EMT in basal-like tumors. a-c Representative

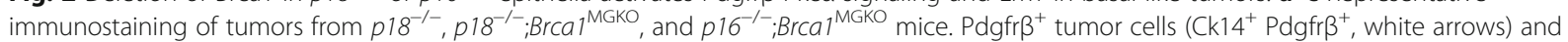

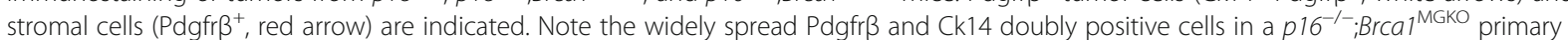
mammary tumor and its lung metastasis (b). d Tumors (T) from two independent $p 18^{-/-} ;$Brca $1^{\text {MGKO }}$ mice (mouse 1, 10 months old; and mouse 2, 18 months old) were analyzed by western blot. Tumor-free mammary glands (MG) from the same mouse were used as controls. e Tumor cells from three independent mice were cultured and analyzed. Protein bands were quantified by Image-Pro Plus 6.0 
a HCC1937
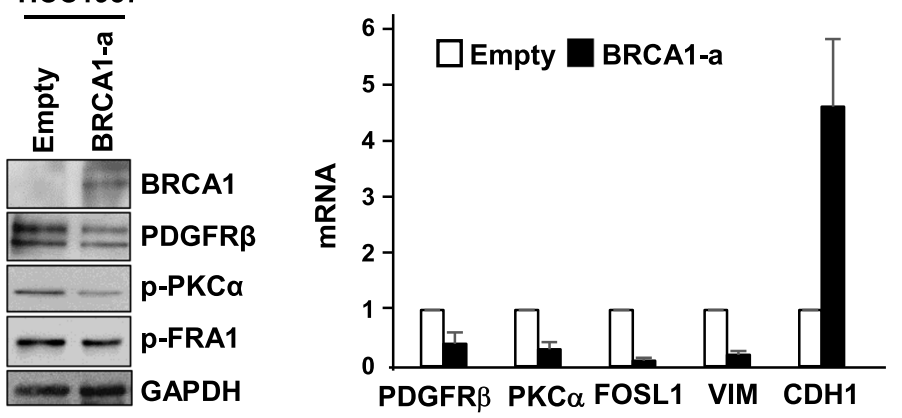

b

MDA-MB231
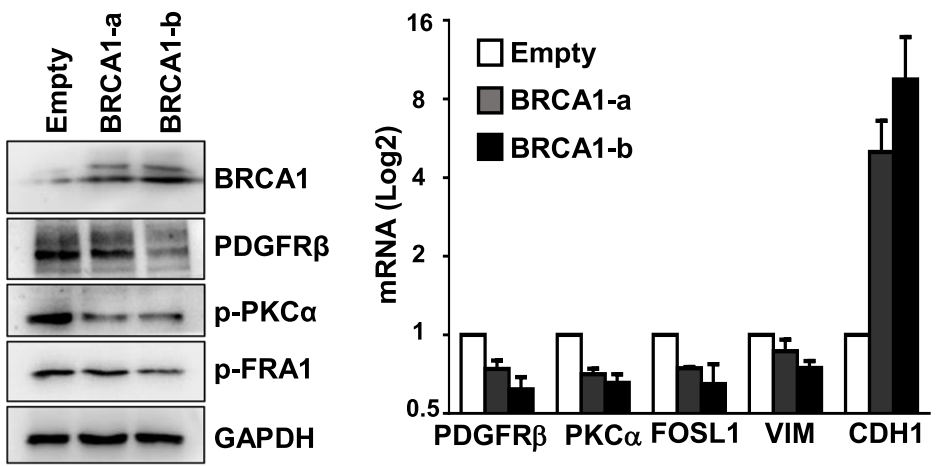

C

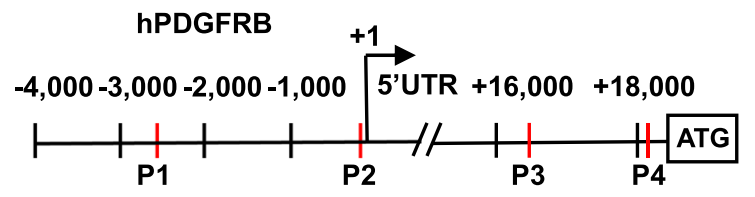

d

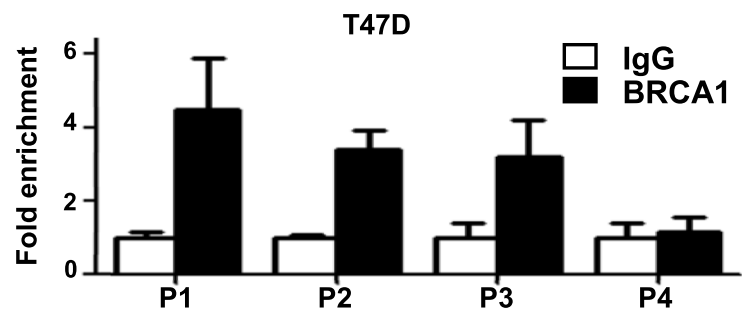

e

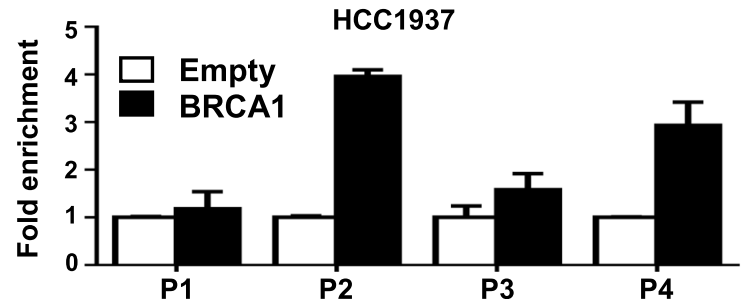

Fig. 3 (See legend on next page.) 
(See figure on previous page.)

Fig. 3 BRCA1 binds to PDGFR $\beta$ locus and represses transcription of PDGFRß and EMT-associated genes. a, b HCC1937 (a) and MDA-MB231 (b) cells were transfected with pBabe-empty (Empty), pBabe-HA-BRCA1 (BRCA1-a), or pBabe-Myc-BRCA1 (BRCA1-b). Expression of genes indicated in the cells were determined by western blot and qRT-PCR $48 \mathrm{~h}$ after transfection. c Diagram showing the location of putative BRCA1 binding sites (red bars) in the human PDGFR $\beta$ gene. +1 , transcription start site. $\mathbf{d}$ ChIP analysis of endogenous BRCA1 binding to the PDGFR $\beta$ locus in T47D cells. The results were normalized to the amount of input and compared with the IgG-negative controls. Data are represented as mean \pm SD. e ChIP analysis of exogenous BRCA1 binding to the PDGFRß locus in HCC1937 cells transfected with Babe-empty (Empty) or pBabe-HA-BRCA1 (BRCA1). The results were normalized to the amount of Input and compared with the empty controls. Data are represented as mean \pm SD

of Brcal in suppressing EMT in a mammary tumor cell autonomous manner.

\section{BRCA1 binds to the PDGFR $\beta$ locus to repress its transcription}

We and others have shown that BRCA1 binds to FOXC1/2 and TWIST loci to repress their transcription $[31,60]$. Our bioinformatic analysis revealed that there exist at least four putative BRCA1 binding sites in the PDGFR $\beta$ locus (Fig. 3c). We performed chromatinimmunoprecipitation (ChIP) assays and found that endogenous and exogenous BRCA1 bound to the PDGFR $\beta$ locus in T47D and HCC1937 cells, respectively (Fig. 3d, e). Together with the inhibitory effect of BRCA1 for the expression of PDGFR $\beta$, these data suggest that BRCA1 binds to the PDGFR $\beta$ locus to repress its transcription.

Targeted deletion of Pdgfr $\beta$ in Brca1-deficient tumor cells promotes cell death and MET suppressing tumorigenesis

To determine the role of Pdgrf $\beta$ in Brca1-deficient tumorigenesis, we knocked out $\operatorname{Pdgfr} \beta$ in $p 18^{-/}$; Brcal $1^{\text {MGKO }}$ primary tumor cells by using the CRISPR/ Cas9 system. We transfected Pdgfr $\beta$ CRISPR/Cas9 KO plasmids (encoding GFP) into $p 18^{-/-} ; \mathrm{Brcal}^{M G K O}$ primary tumor cells. Two days after transfection, GFPnegative $\left(\mathrm{GFP}^{\text {neg }}\right)$ and GFP-positive $\left(\mathrm{GFP}^{\mathrm{pos}}\right)$ cells were FACS sorted for further analysis. We found that GFP pos tumor cells expressed nearly no detectable Pdgfr $\beta$ and drastically reduced p-Pkc $\alpha$, p-Fra1, and Vim, when compared with GFP $^{\text {neg }}$ tumor cells (Fig. 4a). These data confirmed successful depletion of Pdgfr $\beta$ protein in the GFP $^{\text {pos }} p 18^{-/-} ;$Brca1 $1^{\text {MGKO }}$ mammary tumor cells. Additionally, these data also indicate that activation of $\mathrm{Pkc} \alpha$ and its downstream target Fra1 is dependent on Pdgfr $\beta$ signaling, and Pdgfr $\beta$ signaling is required for maintaining the mesenchymal traits in Brcal-deficient tumor cells.

To test the impact of Pdgfr $\beta$ CRISPR/Cas9 KO on tumor cell viability, we performed annexin $\mathrm{V}$ staining. We found that $8.8 \%$ of $\mathrm{GFP}^{\text {pos }}$ (Pdgfr $\beta \mathrm{KO}$ ) tumor cells were positive for annexin $\mathrm{V}$ compared to $4.3 \%$ of the GFP $^{\text {neg }}$ (Pdgfr $\beta$ WT) cells (Fig. 4b). These data indicate that acute deletion of Pdgfr $\beta$ slightly enhances apoptosis of Brca1-deficient tumor cells. We further analyzed FACS-sorted Pdgfr $\beta$ WT and Pdgfr $\beta$ KO $p 18^{-/-}$;
Brca1 $1^{M G K O}$ tumor cells in dishes and observed that the population with characteristic morphological features of apoptosis (i.e., cell shrinkage, pyknosis, dense cytoplasm with tightly packed organelles) or dead cells was significantly increased in Pdgfr $\beta \mathrm{KO}$ cells relative to that in Pdgfr $\beta$ WT cells after 5-7 days of culture (Fig. 4c). We found that the viable cells were significantly less and the dead cells were drastically more in $\operatorname{Pdgfr} \beta \mathrm{KO}$ population than in Pdgfr $\beta$ WT population (Fig. 4d, e). These data indicate that long-term depletion of Pdgfr $\beta$ in $\mathrm{p} 18^{-/-}$;Brca1 $1^{M G K O}$ tumor cells in vitro increases tumor cell death.

We next transplanted freshly FACS-sorted Pdgfr $\beta$ WT and Pdgfr $\beta$ KO $p 18^{-/-} ; B r c a 1^{M G K O}$ tumor cells that were viable into MFPs of NSG mice. We found that Pdgfr $\beta$ WT $p 18^{-/-} ;$Brca1 $1^{M G K O}$ tumor cells generated palpable tumors in 10-14 days whereas Pdgfr $\beta$ KO cells did not generate palpable tumors in the same time period. Four weeks after transplantation, tumors generated by $\operatorname{Pdgfr} \beta$ $\mathrm{KO}$ cells were significantly smaller than tumors generated by Pdgfr $\beta$ WT cells (Fig. 4f). We performed western blot in conjunction with IHC analysis and observed that tumors generated by Pdgfr $\beta$ KO cells expressed clearly reduced levels of Pdgfr $\beta$, p-Pkc $\alpha$, p-Fra1, Vim, Snail, and Twist, but increased levels of E-cad, when compared with tumors generated by Pdgfr $\beta$ WT cells (Fig. 4g, h, and data not shown). Notably, we detected that some cells in tumors generated by $\operatorname{Pdgfr} \beta \mathrm{KO} p 18^{-/-}$; Brca1 $1^{M G K O}$ cells expressed high levels of E-cad, whereas E-cad-positive cells in tumors generated by Pdgfr $\beta$ WT $p 18^{-/-}$;Brca $1^{M G K O}$ tumor cells were rarely observed (Fig. 4h). These results demonstrate that deletion of Pdgfr $\beta$ in Brca1-deficient tumor cells promotes MET and suppresses tumorigenesis.

\section{Inhibition of Pdgfr $\beta$ or Pkca activity suppresses Brca1- deficient tumor initiating potential}

To determine whether Pdgfr $\beta$ and $P k c \alpha$ activity represented therapeutic target in BRCA1-deficient tumors, we treated $p 18^{-/-} ; \mathrm{Brcal}^{M G K O}$ tumor cells with a PDGFR Inh III and PKC $\alpha$ inhibitor, Ro-31-8220. The activity and specificity of these drugs in inhibiting phosphorylation of PDGFR $\beta$ and PKC $\alpha$ have been well confirmed by multiple groups [44, 51, 52, 61]. Illustrating these inhibitors were having the intended 
a

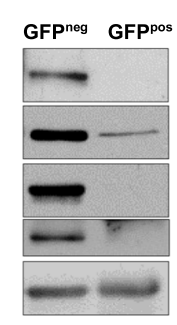

C
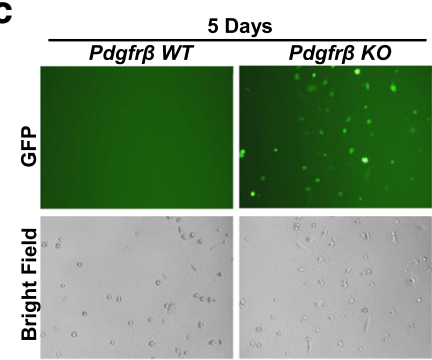

f

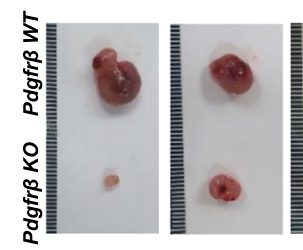

g

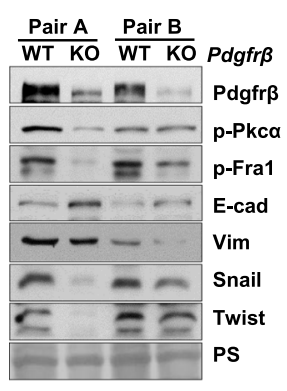

h b
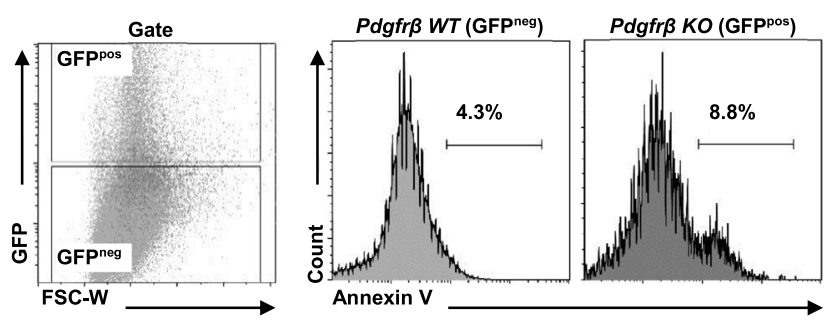

d
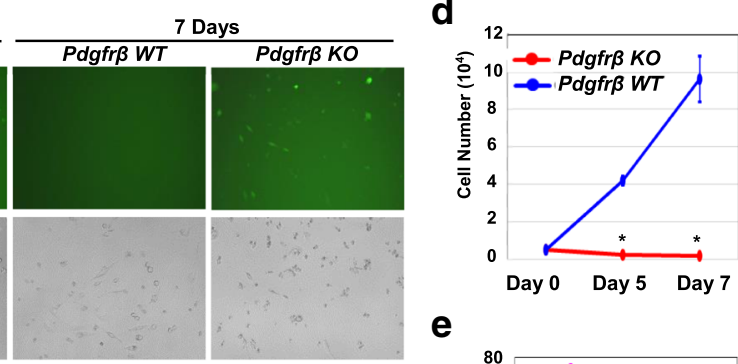

e
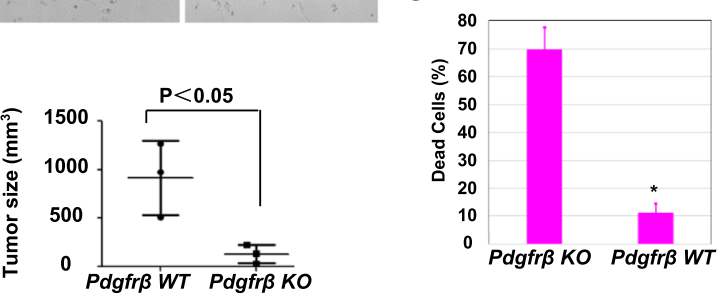

h E-cad
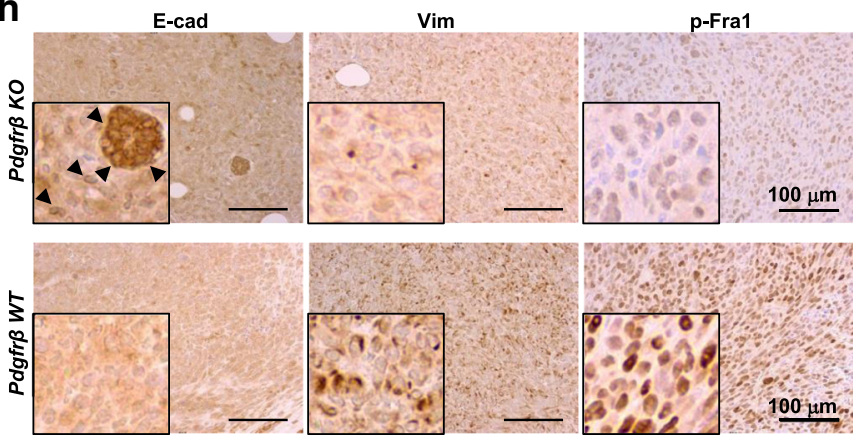

Fig. 4 Deletion of Pdgfr $\beta$ in Brca1-deficient tumor cells promotes cell death, induces MET, and suppresses tumorigenesis. a Primary p1 $18^{-1-} ;$ Brca $^{\text {MGKO }}$ tumor cells were transfected with Pdgfr $B$ CRISPR/Cas9 KO plasmids. Forty-eight hours later, GFPneg and GFPpos cells were sorted

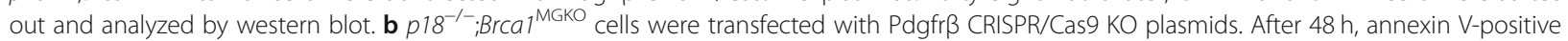

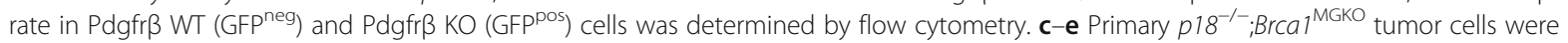
transfected with Pdgfr $\beta$ CRISPR/Cas9 KO plasmids. Forty-eight hours later, FACS-sorted Pdgfr $\beta$ WT (GFPneg) and Pdgfr $\beta$ KO (GFP'Pos) cells were cultured and monitored for additional 7 days (c). The number of viable cells at day 5 and day 7 was counted (d), and the percentage of dead cells at day 7 were calculated (e). The asterisk (*) denotes a significance from Pdgfr $\beta$ WT and Pdgfr $\beta$ KO cells at day 5 or day 7 . $\mathbf{f}$ Freshly sorted Pdgfr $\beta$ WT and $\mathrm{KO} \mathrm{P18}^{-1-} ; \mathrm{Brca}^{\mathrm{MGKO}}$ tumor cells that were viable were transplanted into MFP of NSG mice. Four weeks later, regenerated tumor volumes were determined. Data are represented as mean \pm SD of three tumors in each group. $\mathbf{g}, \mathbf{h}$ Tumors generated from $\mathbf{f}$ were analyzed by western blot $(\mathbf{g})$ and $\mathrm{IHC}(\mathbf{h})$. PS, ponceau staining. The insets show the enlarged cells that are representative. E-cad-positive cells are indicated by arrowheads

effects, we observed reduced Pdgfr $\beta$ and Pkc $\alpha$ phosphorylation following treatment (Fig. 5a, and Additional file 6A, B). In addition, we examined the impact of dosage on tumor cells. Treatment of $p 18^{-/-}$;Brca1 ${ }^{M G K O}$ tumor cells with PDGFR Inh III and Ro-31-8220 significantly reduced cell number and increased cell death, particularly with high dosages
(200 nM for PDGFR Inh III and $350 \mathrm{nM}$ for Ro-318220) (Fig. 5b, c). At a low dosage ( $20 \mathrm{nM}$ for PDGFR Inh III and $35 \mathrm{nM}$ for Ro-31-8220), these drugs converted spindle-shaped, mesenchymal-like cells into epithelial-like cells (Fig. 5d). This is consistent with the data derived from targeted deletion of $\operatorname{Pdgfr} \beta$, and these results further confirm that inhibition of 

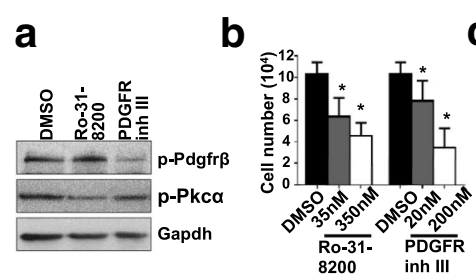

$\mathbf{e}$
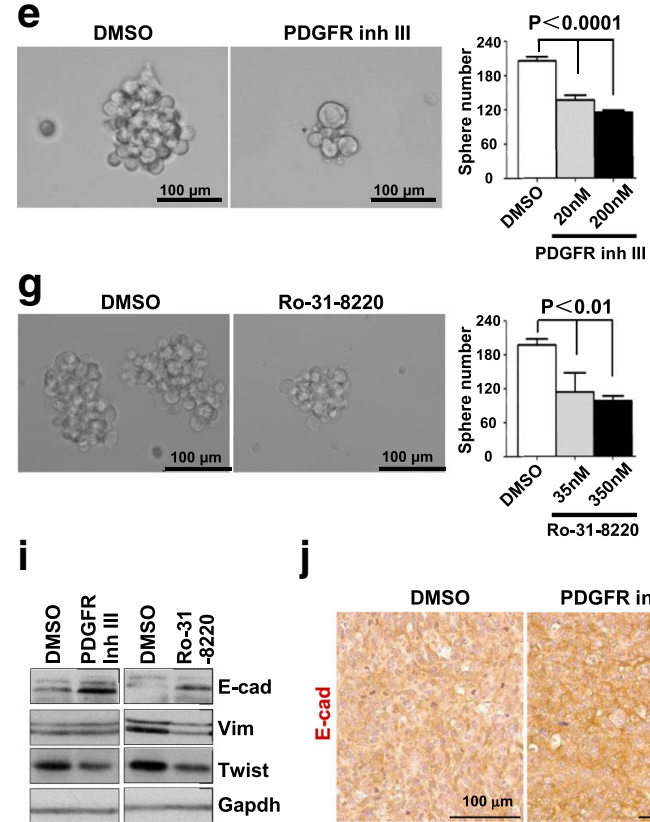

j

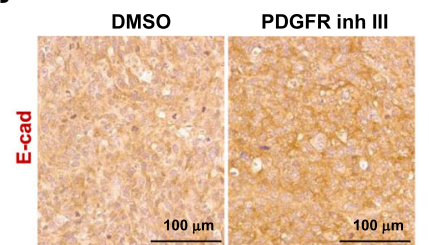

C.

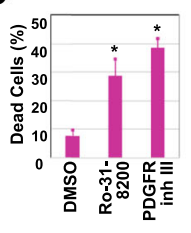

$f$

d

f
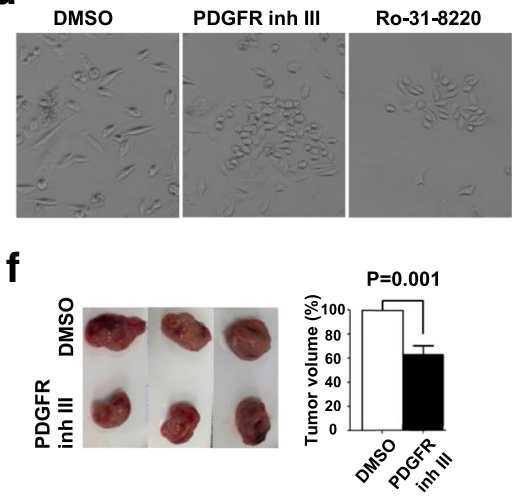

h
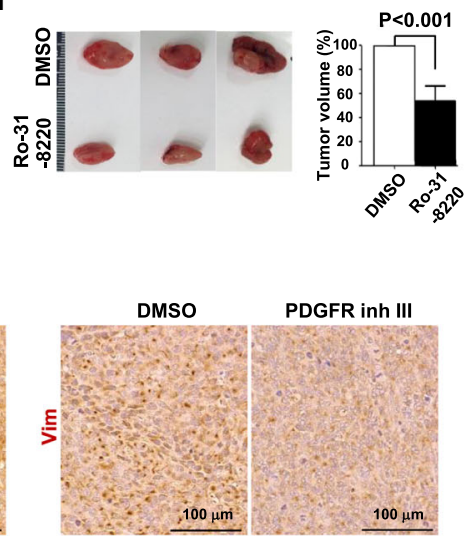

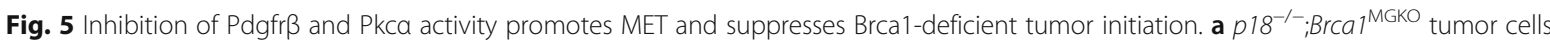

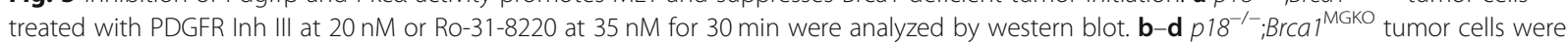
treated with PDGFR Inh III or Ro-31-8220 for 3 days. The number of viable cells was determined (b). The percentage of dead cells treated with PDGFR Inh III at $200 \mathrm{nM}$ or Ro-31-8220 at $350 \mathrm{nM}$ (c) and the morphology of cells treated with PDGFR Inh III at 20 nM or Ro-31-8220 at 35 nM (d) were also analyzed. Data in $\mathbf{b}$ and $\mathbf{c}$ are represented as the mean \pm SD of triplicate experiments. The asterisk $\left({ }^{*}\right)$ denotes a significance from DMSO- and drug-treated cells. e, g Primary $p 18^{-1-} ;$ Brcal ${ }^{\text {MGKO }}$ tumor cells were cultured to generate primary tumorsphere. $10^{4}$ cells dissociated

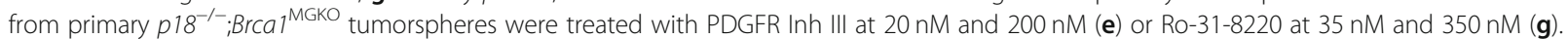
Secondary tumorspheres formed after 6-day treatment were counted from triplicate experiments. Data are represented as the mean \pm SD. $\mathbf{f}, \mathbf{h}$ Cells dissociated from primary $18^{-1-} ;$ Brcal ${ }^{\text {MGKO }}$ tumorspheres were treated with PDGFR Inh III at $20 \mathrm{nM}$ or Ro-31-8220 at $35 \mathrm{nM}$. Six days after treatment, 1000 viable cells pretreated with DMSO, PDGFR Inh III (f), or Ro-31-8220 (h) were transplanted into MFP of NSG mice. Four weeks later, tumor volumes were determined. Data are represented as mean \pm SD of four tumors in each group. $\mathbf{i}, \mathbf{j}$ Tumors generated in $\mathbf{f}$ and $\mathbf{h}$ were analyzed by western blot (i) and IHC (j)

Pdgfr $\beta$-Pkc $\alpha$ signaling promotes Brca1-deficient tumor cell death and MET.

We have previously reported that deletion of Brca1 in p18-deficient mice activates EMT and enhances TICs [31]. We detected that $p 18^{-/-} ; B_{r c a 1}{ }^{M G K O}$ tumor cells formed significantly more and larger spheres than $p 18^{-/-}$cells (data not shown) confirming the role of loss-of-function of Brcal in stimulating TICs. We treated $p 18^{-/-} ; B r c a 1^{M G K O}$ tumorsphere-dissociated cells with PDGFR Inh III or Ro-31-8220 and found that inhibition of Pdgfr $\beta$ or Pkc $\alpha$ activity significantly reduced secondary tumorsphere forming potential (Fig. 5e, g). Moreover, we transplanted $p 18^{-/-} ;$Brcal $^{\text {MGKO }}$ tumorsphere-dissociated cells into NSG mice and found that cells pretreated with low-dose PDGFR Inh III or
Ro-31-8220 produced significantly smaller tumors than control cells (Fig. 5f, h). Western blot and IHC analysis revealed that tumors generated by PDGFR Inh III or Ro31-8220 pretreated cells expressed higher levels of E-cad and lower levels of Vim (Fig. 5i, j) than DMSOpretreated cells. Again, these results confirm that the inhibition of Pdgfr $\beta$ and Pkc $\alpha$ activity promotes MET and reduces Brcal-deficient tumor initiating potential.

\section{Inhibition of Pdgfr $\beta$ or Pkca activity suppresses established Brca1-deficient tumor progression}

We then determined if pharmaceutical inhibition of Pdgfr $\beta$ and Pkc $\alpha$ activity had any effect on the progression of established Brcal-deficient tumors. Transplanted $p 18^{-/-} ; B r c a 1^{M G K O}$ tumors were allowed to reach $150-$ 
$200 \mathrm{~mm}^{3}$ in size and then mice were treated with DMSO or inhibitors daily. Three days after treatment, tumors from PDGFR Inh III- or Ro-31-8220-treated mice began to show a significant size reduction in comparison with the tumors from DMSO-treated animals (Fig. 6a, b). After a 9-day treatment, tumors from DMSO-treated mice reached $578 \pm 265 \mathrm{~mm}^{3}$ in size, whereas those from PDGFR Inh III-treated mice only reached $131 \pm 22 \mathrm{~mm}^{3}$, which was even smaller than that of the tumor size at the start of treatment $\left(194 \pm 48 \mathrm{~mm}^{3}\right.$ ) (Fig. 6a), indicating that treatment with PDGFR Inh III induced regression of Brca1-deficient tumors. Consistently, animals that received Ro-31-8220 treatment for 9 days had a significant reduction in tumor size compared with DMSO treatment controls $\left(772 \pm 366 \mathrm{~mm}^{3}\right.$ vs. $313 \pm 182 \mathrm{~mm}^{3}$,
Fig. 6b). These data demonstrate that pharmaceutical inhibition of Pdgfr $\beta$ and Pkc $\alpha$ activity has therapeutic effects on established Brca1-deficient tumors.

To determine the mechanisms associated with inhibition of tumor progression by Pdgfr $\beta$ and Pkca inhibitors, we analyzed Brca1-deficient tumors by western blot. This revealed that all tumors treated with PDGFR Inh III or Ro-31-8220 expressed more cleaved caspase 3 and less Vim (Fig. 6c, and data not shown), and one expressed higher levels of E-cad when compared with those with DMSO treatment (tumor 5 in Fig. 6c, and data not shown). IHC analysis confirmed that all tumors treated with PDGFR Inh III or Ro-31-8220 displayed more cleaved caspase 3-positive cells than control tumors, though the level of increase varied among tumors
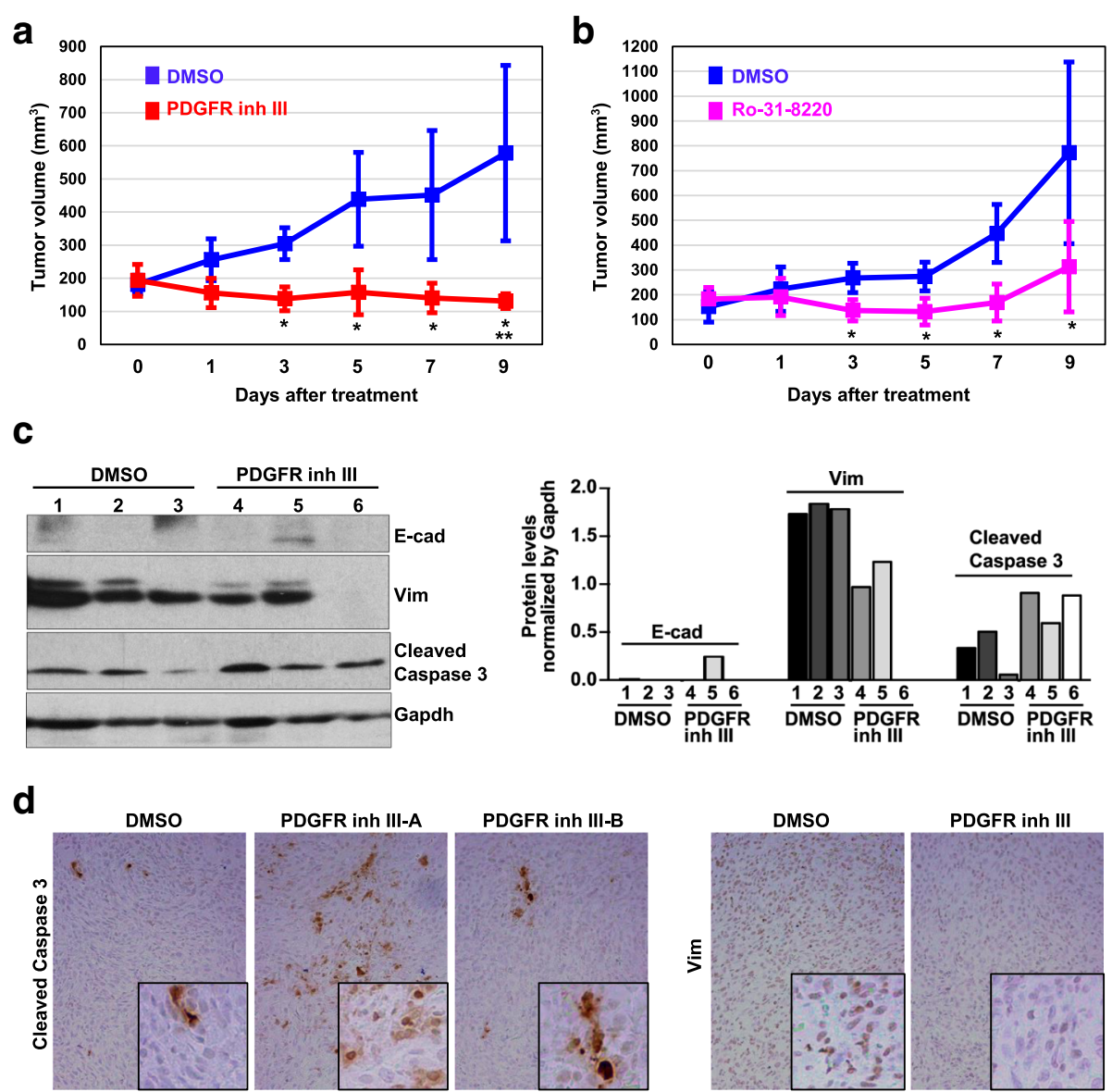

Fig. $\mathbf{6}$ Inhibition of Pdgfr $\beta$ or Pkca activity reduces EMT and promotes apoptosis suppressing established Brca1-deficient tumor progression. $\mathbf{a}$, $\mathbf{b}$

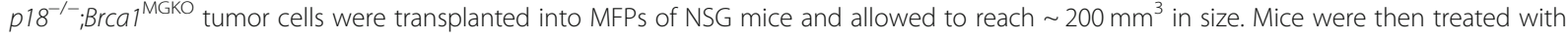
daily i.p. injection of DMSO or PDGFR Inh III at $5 \mathrm{mg} / \mathrm{kg}$ (a) and DMSO or Ro-31-8220 at $5 \mathrm{mg} / \mathrm{kg}$ (b), respectively. The tumor size was determined and plotted. Data are represented as mean \pm SD of four $(\mathbf{a})$ and five $(\mathbf{b})$ tumors in each group. ${ }^{*} p<0.05$ between two groups at each time point by Student $t$ test. ${ }^{* *} p<0.05$ between the group that was at the start of treatment and the group that was treated with PDGFR Inh III for 9 days. $\mathbf{c}$ Representative tumors treated with DMSO (three tumors) or PDGFR Inh III (three tumors) for 9 days were analyzed by western blot (left). The indicated protein levels of each lane were quantified and normalized by that of Gapdh (right). Note the increased cleaved caspase 3 and decreased Vim in PDGFR Inh III-treated samples (lanes 4, 5, and 6) in comparison with those in DMSO-treated samples (lanes 1, 2, and 3). d Representative tumors treated with DMSO or PDGFR Inh III for 9 days were analyzed by IHC. The insets show the enlarged cells that are representative 
and different areas of an individual tumor. All control tumors widely expressed high levels of Vim while PDGFR Inh- or Ro-31-8220-treated tumors showed faint or undetectable Vim (Fig. 6d, and data not shown). In sum, these results suggest that inhibition of $\operatorname{Pdgfr} \beta$ or Pkco activity suppresses tumor progression by reducing mesenchymal features and inducing apoptosis.

\section{Inhibition of PDGFR or PKCa activity efficiently kills BRCA1-deficient human breast cancer cells}

To confirm the cytotoxic effects of inhibition of PDGFR and PKC $\alpha$ on BRCA1-deficient human breast cancer cells, we screened six widely used cell lines including two BRCA1 WT luminal lines, T47D and MCF7; two BRCA1 WT basal lines, MDA-MB231 and BT20; and two BRCA1 mutated lines, HCC1937 and SUM149. Importantly, all these cell lines carry defective INK4-RB pathway (undetectable p16 in T47D, MCF7, MDA-MB231, BT20, SUM149, and undetectable RB in HCC1937) [62-64], which are similar with our $\mathrm{p} 18^{-/-}, \mathrm{p} 18^{-/-} ; \mathrm{Brca}^{\mathrm{MGKO}}$, and p16 ${ }^{-/-} ;$Brca1 ${ }^{\text {MGKO }}$ mouse tumor cell system. We observed that the expression of PDGFR $\beta$ and PKC $\alpha$ was drastically increased in two BRCA1 mutant cell lines (HCC1937 and SUM149) and a BRCA1 lowly expressing MDA-MB231 line, whereas PDGFR $\beta$ and PKC $\alpha$ levels were extremely low in BRCA1 WT luminal lines (T47D and MCF7) and slightly increased in a BRCA1 WT basal line (BT20) (Fig. 7a, b). Western blot analysis revealed that BRCA1 mutant HCC1937 cells expressed significantly higher amounts of PDGFR $\beta$, p-PKC $\alpha$, and p-FRA1 than BRCA1-WT T47D cells (Fig. 7b) which suggested the activation of PDGFR $\beta$-PKC $\alpha$ signaling by BRCA1 loss, consistent with our finding in mice and the findings from others $[44,65]$. We confirmed that PDGFR inh III and Ro-31-8220 suppressed PDGFR $\beta$ and PKC $\alpha$ activities in HCC1937 and T47D cells, though the latter of which exhibited extremely low level of PDGFR $\beta$ and PKC $\alpha$ activities (Additional file $6 \mathrm{~A}, \mathrm{~B})$. We treated these cells with the inhibitors and found that PDGFR Inh III and Ro-318220 significantly reduced the number of viable cells and promoted cell death in BRCA1-mutated HCC1937 and SUM149 cells. In BRCA1 lowly expressing MDA-MB231 cells, these effects were moderate and even more slight in BRCA1 WT luminal cells (Fig. 7c, d, Additional file 6C). Importantly, BRCA1 in BT20 cells was lower than that in luminal cells (MCF7 and T47D), but not as low as that in MDA-MB231 cells. Thus, the slightly increased level of PDGFR $\beta$ and PKC $\alpha$ in BT20 cells relative to that in luminal cells suggested that other factors were involved in inactivation of PDGFR $\beta$ and PKC $\alpha$ and may explain the poor response to PDGFR $\beta$ and PKC $\alpha$ inhibitors in BT20 cells. Together, these data suggest that inhibition of PDGFR or PKC $\alpha$ activity efficiently kills BRCA1-deficient human breast cancer cells.

\section{Expression of BRCA1 is inversely related to that of PDGF $\mathrm{R} \beta$ and $\mathrm{PKC} \alpha$ in breast cancers}

To extend these results to human breast tumors, we performed immunostaining analysis of $8 \mathrm{ER}^{+}$and $10 \mathrm{ER}^{-}$ primary human breast cancers. We found that PDGFR $\beta$, PKC $\alpha$, FRA1, and VIM were readily detected in $\mathrm{ER}^{-}$and BRCA1 weak or non-detectable tumor cells, whereas these proteins were barely detectable in $\mathrm{ER}^{+}$and $\mathrm{BRCA}^{+}$tumor cells (Fig. 7e and Additional file 7A, B). Further analysis revealed that PDGFR $\beta$ and PKC $\alpha$ detected by immunostaining were significantly inversely correlated with BRCA1 expression (Fig. 7f). We then analyzed PDGFR $\beta$ and PKC $\alpha$ mRNA expression in TCGA breast cancer dataset and did not find significant differences of the expression between BRCA1 mutant and WT TNBCs (data not shown). This may be partly resulted from the small sample size of BRCA1 mutant TNBCs in TCGA dataset (PDGFR $\beta$ and PKC $\alpha$ mRNA data are available in only five BRCA1 mutant TNBCs). Moreover, we queried the mRNA expression of genes in the METABRIC 1584 breast cancer sample sets and found a significant inverse correlation between BRCA1 with PDGFR $\beta$ and PKC $\alpha$ mRNA levels (Fig. 7g). These clinical findings, consistent with our results in mice, further confirm that BRCA1 suppresses the PDGFR $\beta$-PKC $\alpha$ signaling pathway in breast basal-like cancer development and progression.

\section{Discussion}

In this study, we showed that heterozygous germline deletion of or epithelium-specific deletion of Brca1 in p18deficient or p16-deficient mice led to basal-like tumors with elevated markers of EMT and Pdgfr $\beta-P k c \alpha$ signaling activity. We demonstrated that BRCA1 bound to the PDGFR $\beta$ locus, repressed PDGFR $\beta$ transcription, and inhibited EMT. Targeted deletion of Pdgfr $\beta$ in Brca1deficient tumor cells inactivated Pdgfr $\beta-P k c \alpha$ signaling, promoted cell death, induced MET, and suppressed tumorigenesis. Consistently, pharmaceutical inhibition of Pdgfr $\beta$ or Pkc $\alpha$ activity suppressed Brca1-deficient tumor initiation and progression. We also found that inhibition of PDGFR or PKC $\alpha$ activity efficiently killed BRCA1-deficient human breast cancer cells and that expression of BRCA1 was inversely related to that of PDGFR $\beta$ and PKC $\alpha$ in human breast cancer samples. These data not only confirm that BRCA1 suppresses EMT and basal-like tumorigenesis in an epitheliumautonomous manner, but also suggest that BRCA1 


\section{a}

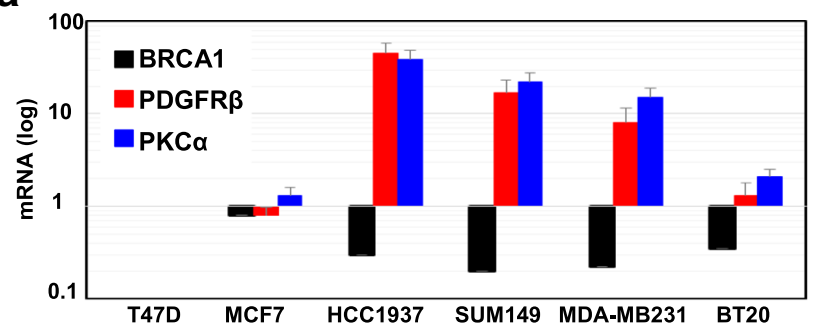

b

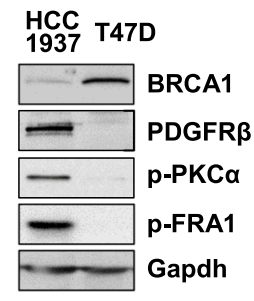

C

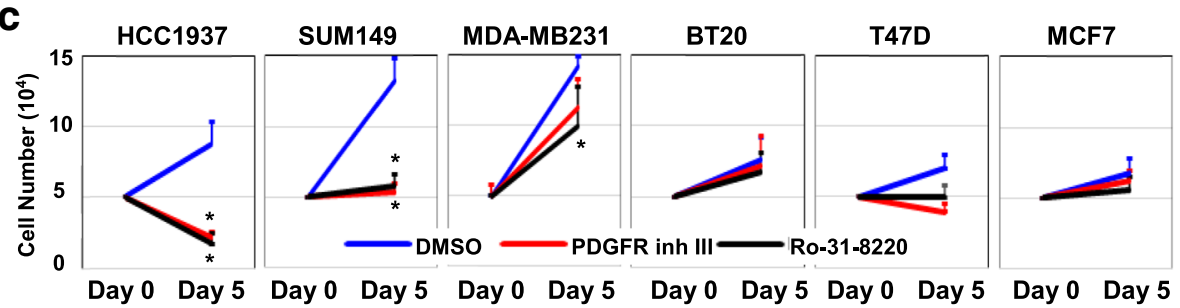

d

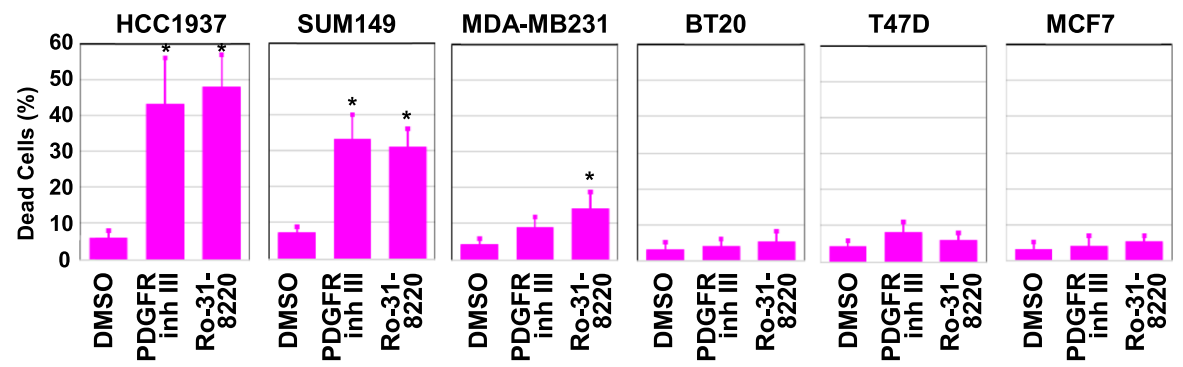

e
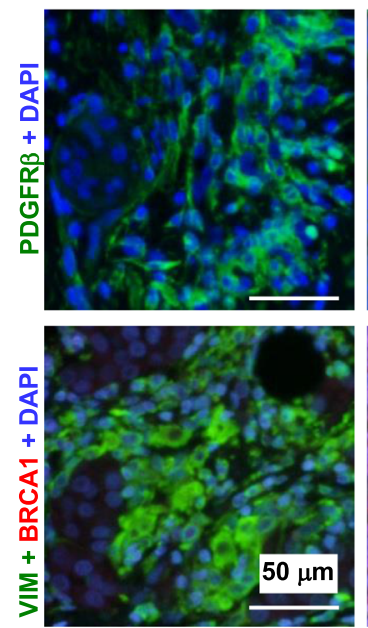

f
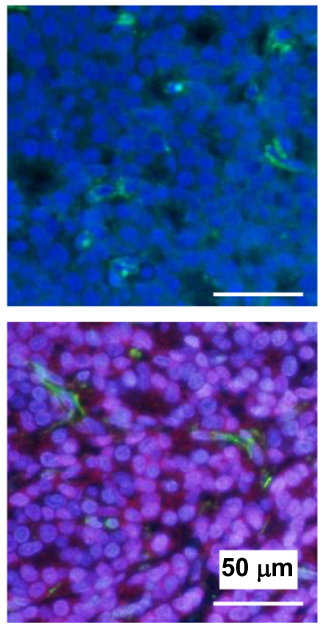

g

\begin{tabular}{|c|c|c|c|c|}
\hline & $\begin{array}{c}\alpha-P D G F R \beta \\
\text { staining* }\end{array}$ & $\begin{array}{c}\alpha-P K C \alpha \\
\text { staining }\end{array}$ \\
\hline $\begin{array}{c}\alpha-B R C A 1 \\
\text { staining }\end{array}$ & High & Low & High & Low \\
\hline High & 1 & 7 & 0 & 8 \\
\hline Low & $7^{*}$ & 3 & $9^{*}$ & 1 \\
\hline
\end{tabular}

\begin{tabular}{|c|c|}
\hline $\begin{array}{l}t \\
\text { (34) }\end{array}$ & $\begin{array}{l}\text { Cor } \\
\text { coe } \\
\text { with } \\
\text { mR }\end{array}$ \\
\hline & $\begin{array}{l}-0 \\
(p\end{array}$ \\
\hline & \\
\hline
\end{tabular}

Fig. 7 Inhibition of PDGFRß or PKCa activity targets BRCA1-deficient breast cancer cells, and expression of BRCA1 is inversely related with that of PDGFR 3 and PKCa in breast cancers. a Expression of BRCA1, PDGFRß, and PKCa mRNA in human breast cancer cell lines was determined by qRTPCR. $\mathbf{b}$ Expression of the proteins indicated in HCC1937 and T47D cells was determined by western blot. c, $\mathbf{d}$ Cancer cells were treated with DMSO, PDGFR Inh III (20 nM), or Ro-31-8220 (35 nM) and the number of viable cells (c) and dead cells (d) was determined after 5 days. Data are represented as mean \pm SD of triplicates. The asterisk (*) denotes a significance from DMSO- and drug-treated cells. e Representative immunostaining analysis of serial human breast cancer sections. $\mathbf{f}$ Summary of the immunostaining results for human breast cancer samples. * "High" expression represents the samples positively stained with an antibody in more than $2 \%$ cells (i.e., scores equal to or higher than " + " in Additional file 7B). "Low" expression represents the samples negative or positively stained with an antibody in less than $2 \%$ cells (i.e., scores less than "+/" in Additional file 7B). The asterisk (*) denotes a significance from BRCA1 high and BRCA1 low tumors by a two-tailed Fisher's exact test. $\mathbf{g}$ Correlation analysis of mRNA levels of BRCA1 and PDGFRß or PKCa for MetaBric breast cancer patients 
suppresses EMT in tumor cells by repressing PDGFR $\beta$ PKC $\alpha$ signaling.

PDGFR $\beta$ is abundantly expressed in normal stromal fibroblasts and in late-stage breast cancer cells, whereas PDGFs, ligands to PDGFR $\beta$, are mainly expressed and secreted in epithelial and carcinoma cells [35-37, 40]. Importantly, in human breast cancers, high stromal PDGFR $\beta$ expression is significantly associated with high histopathological grade, ER negativity, and shorter recurrence-free survival [66]. Indeed, some studies suggest that tumor cells secret PDGF-B as a means of recruiting/activating fibroblasts $[67,68]$. However, it has not yet been shown if stromal cells provide the PDGFs or what impact stromal cells may have on tumor cells with high PDGFR $\beta$. Our study suggests breast cancer phenotypes attributed to PDGFR $\beta$ signaling can be cancer cell intrinsic. Consistent with this, some evidence suggests that breast cancer cells utilize this pathway in an autocrine fashion, producing PDGF-A/B to selfactivate PDGFR $\beta$ [40].

While studies have not examined the prognostic ramifications of tumor-cell PDGF/PDGFR $\beta$ expression, our results here using mouse and human tumors indicate a high likelihood that tumor cell PDGFR $\beta$ staining might provide prognostic information in BRCA1/INK4-RB-deficient tumors. In particular, given our results indicating that Pdgfr $\beta-P k c \alpha$ signaling induces molecular indicators of EMT, we anticipate that BRCA1/INK4-RB-deficient tumors might be more invasive and more likely to develop resistance to chemotherapy. Thus, we anticipate these TNBC patients may require targeted therapies individualized to the unique molecular pathways that enhance the malignancy of BRCA1/INK4-RB-deficient tumors.

Target-specific drugs are available for treating HER2-positive cancers and ER-positive luminal type cancers. Very few therapeutic options are available for highly aggressive and metastatic BLBCs. More than half of BLBCs have a dysfunctional BRCA1 pathway and harbor defects in DNA damage repair [21], which make these patients initially respond well to DNAdamaging agents such as cisplatin and PARP inhibitors. However, tumor recurrence and acquired resistance to DNA-damaging agents combine to decrease the 5-year survival of such patients $[24,69]$. In this report, we find preclinical evidence that $\operatorname{Pdgfr} \beta$ Pkco might serve as one targetable pathway. In particular, given that pharmaceutical inhibition of PDGFR $\beta$ efficiently promotes cell death of BRCA1deficient tumor cells, it indicates the potential to tailor specific therapies to BLBC patients with BRCA1 deficiency. Thus, as a whole, this study uncovers a targetable PDGFR $\beta$-PKC $\alpha$ pathway with biological and therapeutic importance to TNBC.

\section{Conclusions}

Our work offers the first genetic and biochemical evidence that PDGFR $\beta$-PKC $\alpha$ signaling is repressed by BRCA1, which establishes PDGFR $\beta$-PKC $\alpha$ signaling as a therapeutic target for BRCA1-deficient breast cancers. This study not only reveals the molecular mechanism of BRCA1 in suppressing EMT but also tests the efficacy of inhibitors that target PDGFR $\beta$-PKC $\alpha$ signaling on suppressing BRCA1-deficient tumor initiation and progression.

\section{Supplementary Information}

The online version contains supplementary material available at https://doi. org/10.1186/s13058-021-01387-x.

\begin{abstract}
Additional file 1. Primer sequence for accessing the occupancy of BRCA1 on the PDGFR $\beta$ locus.

Additional file 2 The increase of Pdgfr $\beta$ in $p 18^{-/} ; B r C a 1^{+/}$mammary tumors is associated with the activated Pdgf signaling as well as EMT and stem cell signatures. $(\mathrm{A}, \mathrm{B}) \mathrm{p} 18^{-/-} ; \mathrm{BrCa}^{+/-}$tumors expressing high level of Pdgfr $\beta(n=9)$ and low level of Pdgfr $\beta(n=2)$ were analyzed for enrichment of Pdgf pathway (A) and of top correlates made up of EMT and stem cell signatures (B). (C, D) Correlation analysis of Pdgfr $\beta$ with Zeb1 (C) and Twist (D) in $p 18^{-\%} ;$ BrCa $1^{+/}$tumors.

Additional file $\mathbf{3}$ Brca1-deficient mouse mammary tumors express high level of Pdgfr $\beta$ and are metastatic. (A) Representative immunostaining of a $p 16^{-1-} ;$ Brca $^{M G K O}$ mammary tumor and its lung metastasis (M) with antibodies against Pdgfr $\beta$ (Green) and Ck14 (Red). Note the widely expressed $P d g f r \beta$ in primary and metastasized tumors that are Ck14 positive. (B) Representative immunostaining of an additional p18 ${ }^{-/} ;$Brca $1^{M G K O}$ mammary tumor.
\end{abstract}

Additional file $\mathbf{4}$ Loss of Brca1 activates Pdgfrß-Pkca signaling and EMT in mammary tumors. Mammary tumors spontaneously developed in p $18^{-/}$and ${\text {p } 18^{-/} ; \text {Brcal }}^{\mathrm{MGKO}}$ mice were analyzed by western blot.

Additional file 5. BRCA1 represses transcription of PDGFR $\beta$ and EMTassociated genes. SUM149 cells were transfected with pBabe-empty (Empty), pBabe-HA-BRCA1 (BRCA1-a), or pBabe-Myc-BRCA1 (BRCA1-b). Expression of genes indicated in the cells were determined by western blot (A) and qRT-PCR (B) $48 \mathrm{~h}$ after transfection.

Additional file 6 Pharmaceutical inhibition of PDGFR $\beta$ or PKCa activity targets BRCA1 deficient human breast cancer cells. (A, B) HCC1937 (A) and T47D (B) cells treated with DMSO, PDGFR Inh III at $20 \mathrm{nM}$, or Ro-318220 at $35 \mathrm{nM}$ for $24 \mathrm{~h}$ were analyzed by western blot. Due to the extremely low level of PDGFR $\beta$ and PKCa in T47D cells in comparison with that in HCC1937 cells (shown in Fig. 7b), longer exposure bands for T47D cells were shown in (B). N.S., non-specific band. (C) HCC1937 and T47D cells were treated with DMSO, PDGFR Inh III, or Ro-31-8220 at the indicated concentrations for $24 \mathrm{~h}$, and the number of viable cells was determined. Data are represented as mean \pm SD of triplicates. ${ }^{*} p<0.05$ between DMSO and drug treated groups by student t test. ${ }^{* *} p<0.01$ between DMSO and drug treated groups.

Additional file 7. Expression of BRCA1 is inversely related with that of PDGFRß and PKCa in human breast cancers. (A) Representative immunostaining analysis for serial human breast cancer sections. Antibodies used were indicated. (B) Immunostaining results for individual tumor in (A). +/-, <2\%; +, 2-10\%; ++, 10-40\%; +++, 40-70\%; ++++, > $70 \%$

\section{Abbreviations}

ER: Estrogen receptor; EMT: Epithelial-to-mesenchymal transition; p16: p16 ${ }^{\text {INK4A }} ;$ p18: p18 ${ }^{\text {INK4C }} ;$ BLBCs: Basal-like breast cancers; TNBC: Triplenegative breast cancer; TICs: Tumor-initiating cells; PARP: Poly (ADP-ribose) polymerase; INK4: Inhibitors of the CDK4/6; PDGFs: Platelet-derived growth factors; MET: Mesenchymal-to-epithelial transition; CAFs: Cancer-associated 
fibroblasts; ChIP: Chromatin-immunoprecipitation; PDGFR Inh III: PDGFR tyrosine kinase inhibitor III; MECs: Mammary epithelial cells; Brcal $^{\text {MGKO }}$ : Brcal $1^{f / f}$;MMTV-Cre or Brcal ${ }^{f /-}$;MMTV-Cre; IHC: Immunohistochemistry; Vim: Vimentin; E-cad: E-cadherin; MFPs: Mammary fat pads; EMT-TFs: EMT-inducing transcription factors; FACS: Fluorescence-activated cell sorting; ssGSEA: Single sample gene set enrichment analysis; FFPE: Formalin-fixed paraffin-embedded

\section{Acknowledgements}

We thank Drs. Norman Sharpless, Beverly Koller, Chuxia Deng, and Lothar Hennighausen for p16, Brcal mutant and MMTV-cre mice; Joyce Slingerland for discussion; Jerry Usary for critical reading; Emely Pimentel, Jinshan $\mathrm{Ma}$, and Ho Lam Chan for technical support; Marisa Iritani and JunZhu Pei for proofreading; FACS core facility at the University of Miami and Shenzhen University for cell sorting; and the DVR core facility for animal husbandry.

\section{Authors' contributions}

$\mathrm{FB}, \mathrm{SL}$, and $\mathrm{XHP}$ designed the research studies. FB, SL, XL, AS, CW, LZ, and XHP conducted experiments and analyzed data. CF, DPH, and CMP carried out microarray analysis and breast cancer dataset analysis. LF and WGZ provided technical and material support. FB, SL, DPH, and XHP wrote the manuscript. All authors made comments on the manuscript. The authors read and approved the final manuscript.

\section{Funding}

This study was supported by the National Natural Science Foundation of China (81972637), Guangdong Provincial Science and Technology Program (2019B030301009), High-level university phase 2 construction funding from Shenzhen University (860-00000210), Natural Science Foundation of Guangdong Province (2019A1515011343), DOD Idea Expansion Award (W81XWH13-1-0282, USA), IRG-98-277-13 from the American Cancer Society (USA), and research funds from the University of Miami to Xin-Hai Pei.

\section{Availability of data and materials}

All data generated or analyzed during this study are included in this published article and its supplementary information files.

\section{Ethics approval and consent to participate}

The Institutional Animal Care and Use Committee at the University of Miami and Shenzhen University approved all animal procedures.

\section{Consent for publication}

Not applicable.

\section{Competing interests}

The authors have declared that no conflict of interest exists.

\section{Author details}

${ }^{1}$ Guangdong Provincial Key Laboratory of Regional Immunity and Diseases, International Cancer Center, Shenzhen University Health Science Center, Shenzhen 518060, China. ${ }^{2}$ Department of Pathology, Shenzhen University Health Science Center, Shenzhen 518060, China. ${ }^{3}$ Dewitt Daughtry Family Department of Surgery, University of Miami, Miami, FL 33136, USA. ${ }^{4}$ Department of General Surgery, Xiangya Hospital, Central South University, Changsha, China. ${ }^{5}$ Department of Anatomy and Histology, Shenzhen University Health Science Center, Shenzhen 518060, China. ${ }^{6}$ Lineberger Comprehensive Cancer Center, University of North Carolina at Chapel Hill, Chapel Hill, NC 27599, USA. ${ }^{7}$ The Second Affiliated Hospital of Xi'an Jiaotong University, Xi'an 710061, China. ${ }^{8}$ The Affiliated Cancer Hospital of Zhengzhou University, Zhengzhou 450008, China. 'Department of Pharmacology, Shenzhen University Health Science Center, Shenzhen 518039, China. ${ }^{10}$ Department of Biochemistry and Molecular Biology, International Cancer Center, Shenzhen University Health Science Center, Shenzhen 518060, China.

Received: 3 November 2020 Accepted: 3 January 2021

Published online: 21 January 2021

\section{References}

1. Foulkes WD. BRCA1 functions as a breast stem cell regulator. J Med Genet. 2004; $41(1): 1-5$
2. Althuis MD, Fergenbaum JH, Garcia-Closas M, Brinton LA, Madigan MP, Sherman ME. Etiology of hormone receptor-defined breast cancer: a systematic review of the literature. Cancer Epidemiol Biomark Prev. 2004; 13(10):1558-68

3. Wright MH, Calcagno AM, Salcido CD, Carlson MD, Ambudkar SV, Varticovski L. Brca1 breast tumors contain distinct CD44+/CD24- and CD133+ cells with cancer stem cell characteristics. Breast Cancer Res. 2008;10(1):R10.

4. Wicha MS. Cancer stem cell heterogeneity in hereditary breast cancer. Breast Cancer Res. 2008;10(2):105.

5. Lobo NA, Shimono Y, Qian D, Clarke MF. The biology of cancer stem cells. Annu Rev Cell Dev Biol. 2007;23:675-99.

6. Li X, Lewis MT, Huang J, Gutierrez C, Osborne CK, Wu MF, Hilsenbeck SG, Pavlick A, Zhang X, Chamness GC, et al. Intrinsic resistance of tumorigenic breast cancer cells to chemotherapy. J Natl Cancer Inst. 2008;100(9):672-9.

7. Kalluri R, Weinberg RA. The basics of epithelial-mesenchymal transition. J Clin Invest. 2009;119(6):1420-8.

8. Lim E, Vaillant F, Wu D, Forrest NC, Pal B, Hart AH, Asselin-Labat ML, Gyorki $D E$, Ward T, Partanen A, et al. Aberrant luminal progenitors as the candidate target population for basal tumor development in BRCA1 mutation carriers. Nat Med. 2009;15(8):907-13.

9. Proia TA, Keller PJ, Gupta PB, Klebba I, Jones AD, Sedic M, Gilmore H, Tung N, Naber SP, Schnitt S, et al. Genetic predisposition directs breast cancer phenotype by dictating progenitor cell fate. Cell Stem Cell. 2011;8(2):149-63.

10. Molyneux G, Geyer FC, Magnay FA, McCarthy A, Kendrick H, Natrajan R, Mackay A, Grigoriadis A, Tutt A, Ashworth A, et al. BRCA1 basal-like breast cancers originate from luminal epithelial progenitors and not from basal stem cells. Cell Stem Cell. 2010;7(3):403-17.

11. Bai F, Smith MD, Chan HL, Pei XH. Germline mutation of Brca1 alters the fate of mammary luminal cells and causes luminal-to-basal mammary tumor transformation. Oncogene. 2013;32(22):2715-25.

12. Mani SA, Yang J, Brooks M, Schwaninger G, Zhou A, Miura N, Kutok JL, Hartwell K, Richardson AL, Weinberg RA. Mesenchyme Forkhead 1 (FOXC2) plays a key role in metastasis and is associated with aggressive basal-like breast cancers. Proc Natl Acad Sci U S A. 2007;104(24):10069-74.

13. Mani SA, Guo W, Liao MJ, Eaton EN, Ayyanan A, Zhou AY, Brooks M, Reinhard F, Zhang CC, Shipitsin M, et al. The epithelial-mesenchymal transition generates cells with properties of stem cells. Cell. 2008;133(4):70415.

14. Wright MH, Robles Al, Herschkowitz Jl, Hollingshead MG, Anver MR, Perou CM, Varticovski L. Molecular analysis reveals heterogeneity of mouse mammary tumors conditionally mutant for Brca1. Mol Cancer. 2008; 7:29.

15. Ye X, Tam WL, Shibue T, Kaygusuz Y, Reinhardt F, Ng Eaton E, Weinberg RA. Distinct EMT programs control normal mammary stem cells and tumourinitiating cells. Nature. 2015;525(7568):256-60.

16. Haupt B, Ro JY, Schwartz MR. Basal-like breast carcinoma: a phenotypically distinct entity. Arch Pathol Lab Med. 2010;134(1):130-3.

17. Kim MJ, Ro JY, Ahn SH, Kim HH, Kim SB, Gong G. Clinicopathologic significance of the basal-like subtype of breast cancer: a comparison with hormone receptor and Her2/neu-overexpressing phenotypes. Hum Pathol. 2006;37(9):1217-26.

18. Livasy CA, Karaca G, Nanda R, Tretiakova MS, Olopade Ol, Moore DT, Perou CM. Phenotypic evaluation of the basal-like subtype of invasive breast carcinoma. Mod Pathol. 2006;19(2):264-71.

19. Turner $N$, Tutt A, Ashworth A. Hallmarks of 'BRCAness' in sporadic cancers. Nat Rev Cancer. 2004;4(10):814-9.

20. De Summa S, Pinto R, Sambiasi D, Petriella D, Paradiso V, Paradiso A, Tommasi S. BRCAness: a deeper insight into basal-like breast tumors. Ann Oncol. 2013;24(Suppl 8):viii13-21.

21. Koboldt DC, Fulton RS, McLellan MD, Schmidt H, Kalicki-Veizer J, McMichael JF, Fulton LL, Dooling DJ, Ding L, Mardis ER, et al. Comprehensive molecular portraits of human breast tumours. Nature. 2012;487:330-7.

22. Zhu X, Shan L, Wang F, Wang J, Wang F, Shen G, Liu X, Wang B, Yuan Y, Ying J, et al. Hypermethylation of BRCA1 gene: implication for prognostic biomarker and therapeutic target in sporadic primary triple-negative breast cancer. Breast Cancer Res Treat. 2015;150(3):479-86.

23. Drost $\mathrm{R}$, Jonkers J. Opportunities and hurdles in the treatment of BRCA1related breast cancer. Oncogene. 2014;33(29):3753-63.

24. Maxwell KN, Domchek SM. Cancer treatment according to BRCA1 and BRCA2 mutations. Nat Rev Clin Oncol. 2012;9(9):520-8. 
25. Herschkowitz JI, He X, Fan C, Perou CM. The functional loss of the retinoblastoma tumour suppressor is a common event in basal-like and luminal B breast carcinomas. Breast Cancer Res. 2008;10(5):R75.

26. Pei XH, Xiong Y. Biochemical and cellular mechanisms of mammalian CDK inhibitors: a few unresolved issues. Oncogene. 2005;24(17):2787-95.

27. Sherr CJ, McCormick F. The RB and p53 pathways in cancer. Cancer Cell. 2002;2(2):103-12.

28. Pei XH, Bai F, Smith MD, Usary J, Fan C, Pai SY, Ho IC, Perou CM, Xiong Y. CDK inhibitor p18(INK4C) is a downstream target of GATA3 and restrains mammary luminal progenitor cell proliferation and tumorigenesis. Cancer Cell. 2009;15(5):389-401.

29. Kamb A, Gruis NA, Weaver-Feldhaus J, Liu Q, Harshman K, Tavitgian SV, Stockert E, Day RS, Johnson BE, Skolnick MH. A cell cycle regulator potentially involved in genesis of many tumor types. Science. 1994;264:436-40.

30. Herman JG, Merlo A, Mao L, Lapidus RG, Issa J-PJ, Davidson NE, Sidransky D, Baylin SB. Inactivation of the CDKN2/p16/MTS1 gene is frequently associated with aberrant DNA methylation in all common human cancers. Cancer Res. 1995;55:4525-30.

31. Bai F, Chan HL, Scott A, Smith MD, Fan C, Herschkowitz JI, Perou CM, Livingstone AS, Robbins DJ, Capobianco AJ, et al. BRCA1 suppresses epithelial-to-mesenchymal transition and stem cell dedifferentiation during mammary and tumor development. Cancer Res. 2014;74(21):6161-72.

32. Sedic M, Skibinski A, Brown N, Gallardo M, Mulligan P, Martinez P, Keller PJ, Glover E, Richardson AL, Cowan J, et al. Haploinsufficiency for BRCA1 leads to cell-type-specific genomic instability and premature senescence. Nat Commun. 2015;6:7505

33. Scott A, Bai F, Chan HL, Liu S, Ma J, Slingerland JM, Robbins DJ, Capobianco AJ, Pei XH. p16INK4a suppresses BRCA1-deficient mammary tumorigenesis. Oncotarget. 2016;7(51):84496-507.

34. Scott A, Bai F, Chan HL, Liu S, Slingerland JM, Robbins DJ, Capobianco AJ, Pei XH. p16 loss rescues functional decline of Brca1-deficient mammary stem cells. Cell Cycle. 2017;16(8):759-64.

35. Heldin $\mathrm{CH}$. Targeting the PDGF signaling pathway in tumor treatment. Cell Commun Signal. 2013;11:97.

36. Coltrera MD, Wang J, Porter PL, Gown AM. Expression of platelet-derived growth factor B-chain and the platelet-derived growth factor receptor beta subunit in human breast tissue and breast carcinoma. Cancer Res. 1995; 55(12):2703-8

37. Bhardwaj B, Klassen J, Cossette N, Sterns E, Tuck A, Deeley R, Sengupta S, Elliott B. Localization of platelet-derived growth factor beta receptor expression in the periepithelial stroma of human breast carcinoma. Clin Cancer Res. 1996;2(4):773-82.

38. Cirri P, Chiarugi P. Cancer associated fibroblasts: the dark side of the coin. Am J Cancer Res. 2011;1(4):482-97.

39. Pinto MP, Dye WW, Jacobsen BM, Horwitz KB. Malignant stroma increases luminal breast cancer cell proliferation and angiogenesis through plateletderived growth factor signaling. BMC Cancer. 2014;14:735.

40. Jechlinger M, Sommer A, Moriggl R, Seither P, Kraut N, Capodiecci P, Donovan M, Cordon-Cardo C, Beug H, Grunert S. Autocrine PDGFR signaling promotes mammary cancer metastasis. J Clin Invest. 2006;116(6):1561-70.

41. D'Ippolito E, Plantamura I, Bongiovanni L, Casalini P, Baroni S, Piovan C, Orlandi R, Gualeni AV, Gloghini A, Rossini A, et al. miR-9 and miR-200 regulate PDGFRbeta-mediated endothelial differentiation of tumor cells in triple-negative breast cancer. Cancer Res. 2016;76(18):5562-72.

42. Forte L, Turdo F, Ghirelli C, Aiello P, Casalini P, lorio MV, D'llppolito E, Gasparini P, Agresti R, Belmonte B, et al. The PDGFRbeta/ERK1/2 pathway regulates CDCP1 expression in triple-negative breast cancer. BMC Cancer. 2018;18(1):586

43. Dhillon AS, Tulchinsky E. FRA-1 as a driver of tumour heterogeneity: a nexus between oncogenes and embryonic signalling pathways in cancer. Oncogene. 2015;34(34):4421-8.

44. Tam WL, Lu H, Buikhuisen J, Soh BS, Lim E, Reinhardt F, Wu ZJ, Krall JA, Bierie B, Guo W, et al. Protein kinase C alpha is a central signaling node and therapeutic target for breast cancer stem cells. Cancer Cell. 2013;24(3):347-64

45. Hollier BG, Tinnirello AA, Werden SJ, Evans KW, Taube JH, Sarkar TR, Sphyris N, Shariati M, Kumar SV, Battula VL, et al. FOXC2 expression links epithelialmesenchymal transition and stem cell properties in breast cancer. Cancer Res. 2013;73(6):1981-92.

46. Xu X, Wagner KU, Larson D, Weaver Z, Li C, Ried T, Hennighausen L, Wynshaw-Boris A, Deng CX. Conditional mutation of Brca1 in mammary epithelial cells results in blunted ductal morphogenesis and tumour formation. Nat Genet. 1999;22(1):37-43.

47. Wagner KU, Wall RJ, St-Onge L, Gruss P, Wynshaw-Boris A, Garrett L, Li M, Furth PA, Hennighausen L. Cre-mediated gene deletion in the mammary gland. Nucleic Acids Res. 1997;25(21):4323-30.

48. Franklin DS, Godfrey VL, Lee H, Kovalev Gl, Schoonhoven R, Chen-Kiang S, Su L, Xiong Y. CDK inhibitors $p 18^{I N K 4 C}$ and $p 27^{K I P 1}$ mediate two separate pathways to collaboratively suppress pituitary tumorigenesis. Genes Dev. 1998;12:2899-911.

49. Gowen LC, Johnson BL, Latour AM, Sulik KK, Koller BH. Brca1 deficiency results in early embryonic lethality characterized by neuroepithelial abnormalities. Nat Genet. 1996;12(2):191-4.

50. Sharpless NE, Bardeesy N, Lee KH, Carrasco D, Castrillon DH, Aguirre AJ, Wu EA, Horner JW, DePinho RA. Loss of $p 16^{\text {Ink4a }}$ with retention of p19 $19^{\text {Arf }}$ predisposes mice to tumorigenesis. Nature. 2001;413(6851):86-91.

51. Matsuno K, Ushiki J, Seishi T, Ichimura M, Giese NA, Yu JC, Takahashi S, Oda S, Nomoto Y. Potent and selective inhibitors of platelet-derived growth factor receptor phosphorylation. 3. Replacement of quinazoline moiety and improvement of metabolic polymorphism of 4-[4-(N-substituted (thio)carbamoyl)-1-piperazinyl]-6,7-dimethoxyquinazoline derivatives. J Med Chem. 2003:46(23):4910-25.

52. Wilkinson SE, Parker PJ, Nixon JS. Isoenzyme specificity of bisindolylmaleimides, selective inhibitors of protein kinase C. Biochem J. 1993;294(Pt 2):335-7.

53. Herschkowitz JI, Simin K, Weigman VJ, Mikaelian I, Usary J, Hu Z, Rasmussen KE, Jones LP, Assefnia S, Chandrasekharan S, et al. Identification of conserved gene expression features between murine mammary carcinoma models and human breast tumors. Genome Biol. 2007;8(5):R76.

54. Subramanian A, Tamayo P, Mootha VK, Mukherjee S, Ebert BL, Gillette MA, Paulovich A, Pomeroy SL, Golub TR, Lander ES, et al. Gene set enrichment analysis: a knowledge-based approach for interpreting genome-wide expression profiles. Proc Natl Acad Sci U S A. 2005;102(43):15545-50.

55. Jassal B, Matthews L, Viteri G, Gong C, Lorente P, Fabregat A, Sidiropoulos K, Cook J, Gillespie M, Haw R, et al. The reactome pathway knowledgebase. Nucleic Acids Res. 2020;48(D1):D498-503.

56. Hollern DP, Swiatnicki MR, Andrechek ER. Histological subtypes of mouse mammary tumors reveal conserved relationships to human cancers. PLoS Genet. 2018;14(1):e1007135.

57. Lim E, Wu D, Pal B, Bouras T, Asselin-Labat ML, Vaillant F, Yagita H, Lindeman GJ, Smyth GK, Visvader JE. Transcriptome analyses of mouse and human mammary cell subpopulations reveal multiple conserved genes and pathways. Breast Cancer Res. 2010;12(2):R21.

58. Curtis C, Shah SP, Chin SF, Turashvili G, Rueda OM, Dunning MJ, Speed D, Lynch AG, Samarajiwa S, Yuan Y, et al. The genomic and transcriptomic architecture of 2,000 breast tumours reveals novel subgroups. Nature. 2012; 486(7403):346-52.

59. Wang C, Bai F, Zhang LH, Scott A, Li E, Pei XH. Estrogen promotes estrogen receptor negative BRCA1-deficient tumor initiation and progression. Breast Cancer Res. 2018;20(1):74.

60. Tkocz D, Crawford NT, Buckley NE, Berry FB, Kennedy RD, Gorski JJ, Harkin DP, Mullan PB. BRCA1 and GATA3 corepress FOXC1 to inhibit the pathogenesis of basal-like breast cancers. Oncogene. 2012;31(32):3667-78.

61. Kim Y, Kim E, Wu Q, Guryanova O, Hitomi M, Lathia JD, Serwanski D, Sloan $A E$, Weil RJ, Lee J, et al. Platelet-derived growth factor receptors differentially inform intertumoral and intratumoral heterogeneity. Genes Dev. 2012; 26(11):1247-62.

62. Elstrodt F, Hollestelle A, Nagel JH, Gorin M, Wasielewski M, van den Ouweland A, Merajver SD, Ethier SP, Schutte M. BRCA1 mutation analysis of 41 human breast cancer cell lines reveals three new deleterious mutants. Cancer Res. 2006;66(1):41-5.

63. Hollestelle A, Nagel JH, Smid M, Lam S, Elstrodt F, Wasielewski M, Ng SS, French PJ, Peeters JK, Rozendaal MJ, et al. Distinct gene mutation profiles among luminal-type and basal-type breast cancer cell lines. Breast Cancer Res Treat. 2010;121(1):53-64.

64. Arima Y, Hayashi N, Hayashi H, Sasaki M, Kai K, Sugihara E, Abe E, Yoshida A, Mikami S, Nakamura S, et al. Loss of p16 expression is associated with the stem cell characteristics of surface markers and therapeutic resistance in estrogen receptor-negative breast cancer. Int J Cancer. 2012;130(11):2568-79.

65. Hsu YH, Yao J, Chan LC, Wu TJ, Hsu JL, Fang YF, Wei Y, Wu Y, Huang WC, Liu CL, et al. Definition of PKC-alpha, CDK6, and MET as therapeutic targets in triple-negative breast cancer. Cancer Res. 2014;74(17):4822-35. 
66. Paulsson J, Sjoblom T, Micke P, Ponten F, Landberg G, Heldin CH, Bergh J, Brennan DJ, Jirstrom K, Ostman A. Prognostic significance of stromal platelet-derived growth factor beta-receptor expression in human breast cancer. Am J Pathol. 2009:175(1):334-41.

67. Ostman A, Augsten M. Cancer-associated fibroblasts and tumor growth--bystanders turning into key players. Curr Opin Genet Dev 2009;19(1):67-73.

68. Pietras K, Pahler J, Bergers G, Hanahan D. Functions of paracrine PDGF signaling in the proangiogenic tumor stroma revealed by pharmacological targeting. PLoS Med. 2008;5(1):e19.

69. Lord CJ, Tutt AN, Ashworth A. Synthetic lethality and cancer therapy: lessons learned from the development of PARP inhibitors. Annu Rev Med. 2015;66:455-70

\section{Publisher's Note}

Springer Nature remains neutral with regard to jurisdictional claims in published maps and institutional affiliations.

Ready to submit your research? Choose BMC and benefit from:

- fast, convenient online submission

- thorough peer review by experienced researchers in your field

- rapid publication on acceptance

- support for research data, including large and complex data types

- gold Open Access which fosters wider collaboration and increased citations

- maximum visibility for your research: over $100 \mathrm{M}$ website views per year

At $\mathrm{BMC}$, research is always in progress.

Learn more biomedcentral.com/submissions 